\title{
Predicting the liquefaction potential of soil layers in Tabriz city via artificial neural network analysis
}

\author{
Mohammad Alizadeh Mansouri ${ }^{1} \cdot$ Rouzbeh Dabiri $^{1}$ (i)
}

Received: 18 February 2021 / Accepted: 14 June 2021

Published online: 30 June 2021

(c) The Author(s) 2021 OPEN

\begin{abstract}
Soil liquefaction is a phenomenon through which saturated soil completely loses its strength and hardness and behaves the same as a liquid due to the severe stress it entails. This stress can be caused by earthquakes or sudden changes in soil stress conditions. Many empirical approaches have been proposed for predicting the potential of liquefaction, each of which includes advantages and disadvantages. In this paper, a novel prediction approach is proposed based on an artificial neural network (ANN) to adequately predict the potential of liquefaction in a specific range of soil properties. To this end, a whole set of 100 soil data is collected to calculate the potential of liquefaction via empirical approaches in Tabriz, Iran. Then, the results of the empirical approaches are utilized for data training in an ANN, which is considered as an option to predict liquefaction for the first time in Tabriz. The achieved configuration of the ANN is utilized to predict the liquefaction of 10 other data sets for validation purposes. According to the obtained results, a well-trained ANN is capable of predicting the liquefaction potential through error values of less than $5 \%$, which represents the reliability of the proposed approach.
\end{abstract}

Keywords Liquefaction · Stochastic finite-fault modeling · Artificial neural network · Support vector machine · Tabriz city

\section{Introduction}

Liquefaction in soil due to an earthquake is one of the important phenomena and causes severe damages to structures and lifelines. During an earthquake, the pore water pressure increases in loose saturated granular soils (and clayey soils in special conditions), and then, the soil tends to reduce its volume to confine the stress. Finally, shear strength in the soil is about equal to zero, and liquefaction happens in this state. This phenomenon occurs in conditions such as extended ground settlements, sand boiling, and water seepage on the ground. Several factors, such as earthquake magnitude and duration, void ratio, relative density, fines content, and plasticity index can affect the occurrence of liquefaction [42]. Liquefaction resistance of soils can be evaluated using laboratory tests, such as cyclic simple shear test, cyclic triaxial tests, and cyclic torsional test or field tests (e.g., standard penetration test, SPT) [24], cone penetration test (CPT) [39], and shear wave velocity (Vs) [1, 2]. Artificial neural networks (ANNs) or synthetic neural networks or, simply, neural networks, are new computational systems and methods for machine learning, knowledge demonstration, and ultimately applied knowledge acquisition to maximize the outputs of complex systems. The idea behind these networks is partly inspired by the way the biological nervous system works to process information for learning and creating knowledge. A key element of this idea is to create new structures in the information processing system. It consists of a large number of highly interconnected processing

Rouzbeh Dabiri, rouzbeh_dabiri@iaut.ac.ir | 'Department of Civil Engineering, Tabriz Branch, Islamic Azad University, Tabriz, Iran.

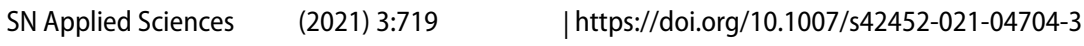


elements, called neurons, which work together to solve a problem and transmit information through synapses (electromagnetic communications). If one cell is damaged in these networks, the rest of the cells can compensate for their absence and contribute to its regeneration. These networks are capable of learning. By burning the touch nerve cells, for example, the cells learn not to move toward the hot object, and with this algorithm, the system learns to correct its error. The learning process is adaptive in these systems. For example, it can happen via using the weight of the synapses that is altered to produce a correct response when new inputs are generated. The main aim of this paper is to utilize some intelligent techniques in overcoming the mentioned issues in dealing with liquefaction. This paper proposes a novel prediction approach based on an ANN to adequately predict the liquefaction potential for a specific range of soil properties. Since ANN is a fairly respected tool for response prediction, utilizing this intelligent method is a challenging act that is addressed in this paper. For this purpose, a whole set of 100 soil data is collected to calculate the liquefaction potential using empirical approaches in Tabriz, Iran. Then, the results of the empirical approaches are utilized for data training in an ANN, which is considered as an option to predict the liquefaction. The archived configuration of the ANN is utilized for predicting the liquefaction of 10 other data sets for validation purposes. It should be noted that the liquefaction prediction in Tabriz city is conducted for the first time in this study, and therefore, the results of this paper should be utilized for future applications in different fields. Many studies have been conducted to develop empirical prediction approaches for the liquefaction phenomenon.

A majority of these studies have been conducted in the most important areas of the world [7, 15, 19, 24, 30, 36, $37,45]$. Recently, the utilization of neural networks has increased for liquefaction prediction due to the development of computer systems. Some of the previous studies are briefly indicated here. Xue and Liu [49] proposed two optimization techniques, namely genetic algorithm (GA) and particle swarm optimization (PSO), to improve the efficiency of a backpropagation (BP) neural network model in predicting the liquefaction susceptibility of soils. The study concluded that the proposed PSO-BP model improves the classification accuracy and is a feasible way to predict soil liquefaction. Xue et al. [50] presented the hybrid probabilistic neural network (PNN) and particle swarm optimization (PSO) techniques to predict soil liquefaction. The PSO algorithm is employed in selecting the optimal smoothing parameter of the PNN to improve the forecasting accuracy. The study concluded that the proposed PSO-PNN model could be used as a reliable approach for predicting soil liquefaction. Zhang and Goh [51] assessed the liquefaction of soils based on the capacity energy concept and backpropagation neural networks. They presented the model accuracy, model interpretability, and procedures to perform a parameter with relative importance for the prediction process. Asvar et al. [3] discussed blast-induced liquefaction for estimating the residual pore pressure ratio through a multilayer perceptron neural network, in which an error (RMS) of 0.105 was calculated for the network. Next, the neuro-fuzzy network, ANFIS, was used for modeling. Different ANFIS models were created using grid partitioning (GP), subtractive clustering (SCM), and fuzzy $\mathrm{C}$-means clustering (FCM). The results revealed that the SPT was the most effective factor in determining the blastinduced liquefaction. Kurnaz and Kaya [31] presented a novel ensemble group method of a data handling model, called EGMDH, based on a classification for predicting the liquefaction potential of soils. The database used in this study consisted of 212 CPT-based field records from eight major earthquakes. The results indicated that the proposed EGMDH model achieved more successful results in predicting the liquefaction potential of soils than the other classifier models via improving the performance prediction of the GMDH model.

Some other works have been done in recent years. Hwang et al. [23] evaluated the soil liquefaction potential regarding an update of the HBF method focusing on research and practice in Taiwan. Njock et al. [35] presented the evaluation of soil liquefaction using the Al technology incorporating a coupled ENN/t-SNE model. Das et al. [16] proposed multi-objective feature selection (MOFS) algorithms for the prediction of liquefaction susceptibility of soil based on in situ test methods. Mele and Flora [32] predicted the liquefaction resistance of unsaturated sands and achieved outstanding results. Shahri and Moud [44] analyzed the liquefaction potential using a hybrid multiobjective intelligence model. The novelty of this paper can be considered from two specific perspectives. The first is that the liquefaction has not been considered in Tabriz city as the case study of this paper, and the second is the application of ANN in the liquefaction prediction. Since the empirical equations are not sufficient for parameter determination of physical phenomena, it is necessary to utilize artificial intelligence. Therefore, this paper aims to use these actions in predicting one of the most difficult physical problems on the earth.

\section{General conditions and geology in the study area}

The city of Tabriz is one of the largest cities in Iran in the Azerbaijan region, with a population of more than $2,500,000$ people. This city is surrounded by the Eynali mountain range in the east-west and not-so-high 
consolidated alluvial deposits and conglomerates in the south. The general slope of the plain is toward the west, and as a result, the direction of the general drainage of the surface and underground water is also westward. The surface of the plain is generally covered by alluvial deposits. The average height of the city of Tabriz is $1340 \mathrm{~m}$ above sea level (Fig. 1). With respect to stratigraphy, Azerbaijan has a long period of expansion, and there are also extensive Cambrian outcrops in the surroundings of the Tabriz plain. However, the stones and the alluvium in the area of Tabriz do not date back to such a time period, with their formation components being related to the Cenozoic and Quaternary periods. The Cainozoic component in the Tabriz plain started from the Miocene Age and lasted up to the Quaternary era (Table 1). The alluvial of the fourth period including, soft to hard conglomerates, is located on this sediment [30].

Also, the city of Tabriz is located in the west of the Alborz zone and follows the governing tectonic regimes. The formation of the Tabriz plain sediment in it and the formation of tectonic structures, which often emerge as fractures or faults, follow this system. The Tabriz plain is surrounded by the mountains of Eynali in the north and by the volcanic altitudes of Sahand and its pyroclastic sediments in the south. The reverse function of the North Tabriz Fault with the slope to the north caused the collapse of its southern part. As a result, the southern plains were created parallel to the northern part fractures with
Table 1 Geological sequences and formations of Tabriz city [20]

\begin{tabular}{ll}
\hline Quaternary & Alluvium \\
\hline Pliocene & Fish beds (marl, lapilli, diatomite) \\
Miocene & $\begin{array}{c}\text { Baghmishe formation (marl with shale and lignite) } \\
\text { Upper red formation (marl, sandstone, and clay- } \\
\text { stone with a layer of gypsum) }\end{array}$ \\
\hline
\end{tabular}

normal displacement, resulting in a gardenlike collapse of the east-west continuation. The current formation on which Tabriz is located is the result of such a collapse. As a result of this collapse, the rest of the Miocene and pyroclastic sediment of the east and the south of the city are observable in lower height balances. Furthermore, the erosive function due to the entrance of the big rivers caused the deposit of alluvial material with high thickness in the plain. Particle reduction is expected due to the headwaters of the river from the south and the east of the Tabriz plain and its elongation in an east-west state by moving toward the west. The area is tectonically active according to the fault system activity and the earthquakes that occurred in the region and observation of fractures in younger sediments. Iran is located in the Alpine-Himalayan belt as one of the world's most important seismic belts. Azerbaijan province is also located in this belt and experienced destructive earthquakes in the past. There are many large and small faults in the region that may cause

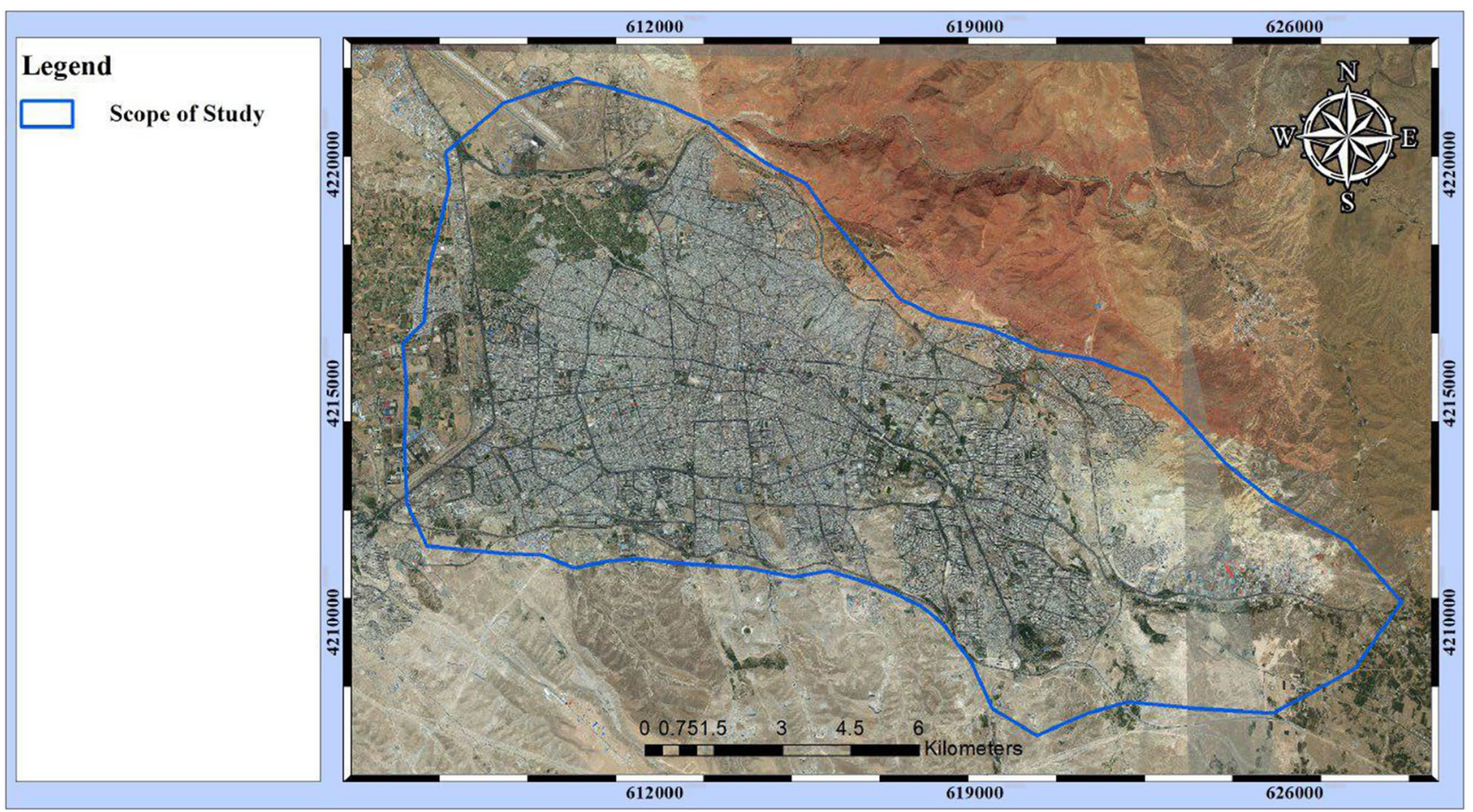

Fig. 1 The scope of the study area 
destructive tremors [20]. The level of the groundwater can be considered as one of the main factors in the assessment of the liquefaction potential of the soils. The results of the study showed that there were not many changes in the groundwater level after being static, and a higher level of the groundwater was observed in spring. The balance of the groundwater decreased from the east to the west, showing that the water flow was from the east to the west, corresponding to the slope of the Tabriz plain. Groundwater depth variations in the city of Tabriz are shown in Fig. 2.

Once more, the peak ground acceleration (PGA) of the study area should be assessed to analyze the boreholes and identify the liquefaction potential of soil layers. The length of the Tabriz north fault from Bostan abad to Sofian cities is at least $90 \mathrm{~km}$, but it seems to continue toward the southeast and the northwest (Fig. 2). Therefore, the PGA in the study area and soil layers were assessed according to the stochastic finite-fault modeling to analyze the site response.

\subsection{Stochastic finite-fault modeling}

Motazedian and Atkinson [34] proposed a method to simulate earthquake seismogram using the stochastic finite-fault method relying on dynamic corner frequency. In their method, more accurate results are obtained because high frequencies are generated using the Boore random method, and at the same time, it has the ability to generate short frequencies using the analytical method and simulate their combination. In this method, the fault is divided into smaller parts $(N)$, called sub-faults, and each part is assumed as a point-source. The rupture starts from a given point (seismic focus), and when it reaches any part, that part releases its energy. The main earthquake related to all faults is obtained by adding small events from each sub-fault at the site and based on their time delay. The explanation of this process is shown in Fig. 3.

EXSIM is an open-source stochastic finite-source simulation algorithm, which is written in FORTRAN and generates the time series of the ground motion for the earthquakes. In the finite-fault modeling of the ground motion, a large fault is categorized into $N$ sub-faults where each sub-fault is considered as a small point-source. The ground motion contributed to each sub-fault can be calculated by the stochastic point-source method and then summed at the observation point with a proper time delay in order to obtain the ground motion from the entire fault. The time series from the sub-sources are modeled using the pointsource stochastic model developed by Boore $[9,10]$ and popularized by the Stochastic-Method Simulation computer code $[10,11]$. Furthermore, the ground motion from each sub-source is treated as the random Gaussian noise of a specified duration by having an underlying spectrum as given by the point-source model [13] for shear radiation. This basic idea was implemented in many studies (e.g., $[4,8,12,25-27,34,41])$. Motazedian and Atkinson

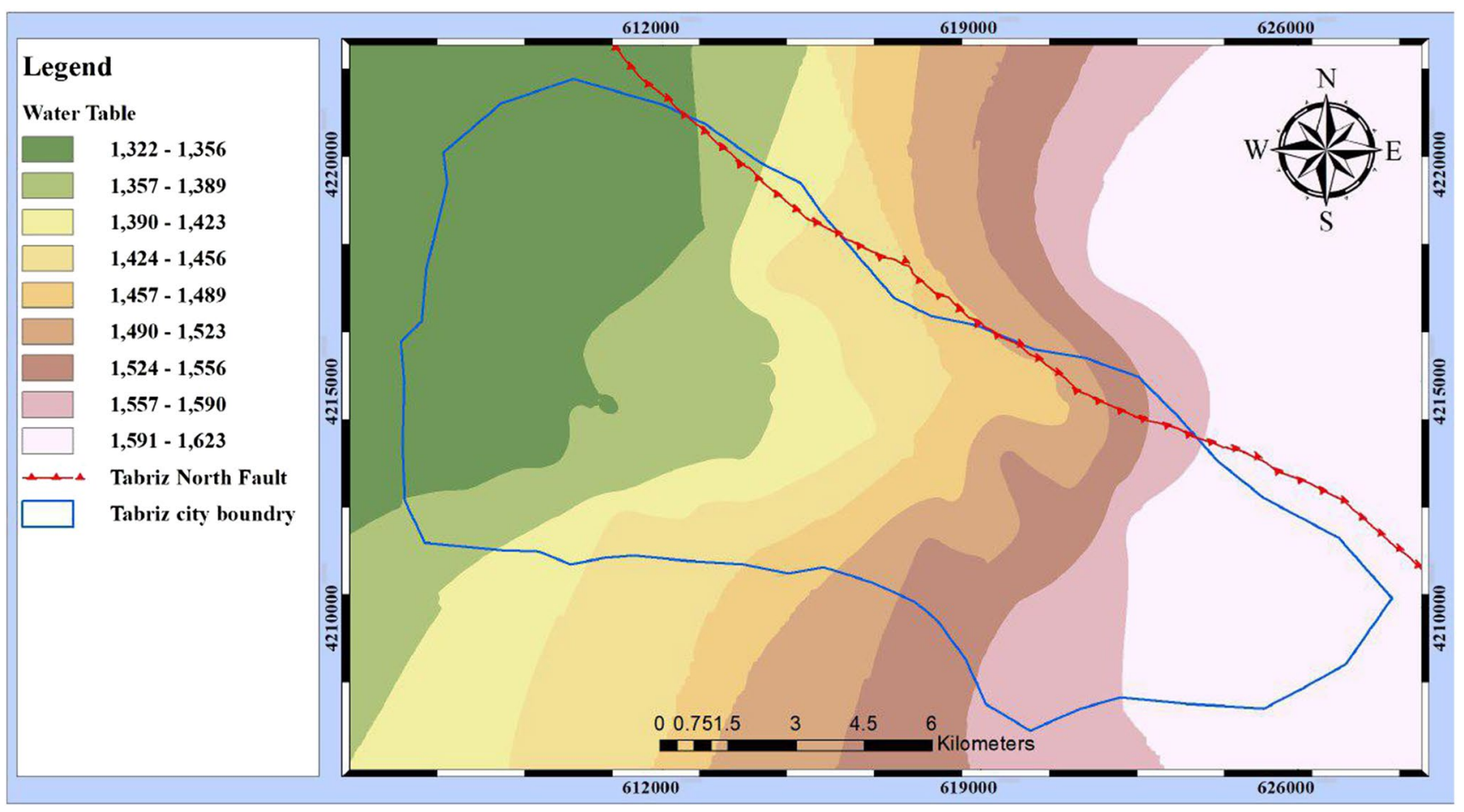

Fig. 2 Variations of the water table in depth below the ground level in the study area 
Fig. 3 Finite-fault model for dividing the fault plane into $\mathrm{N}$ sub-faults [34]
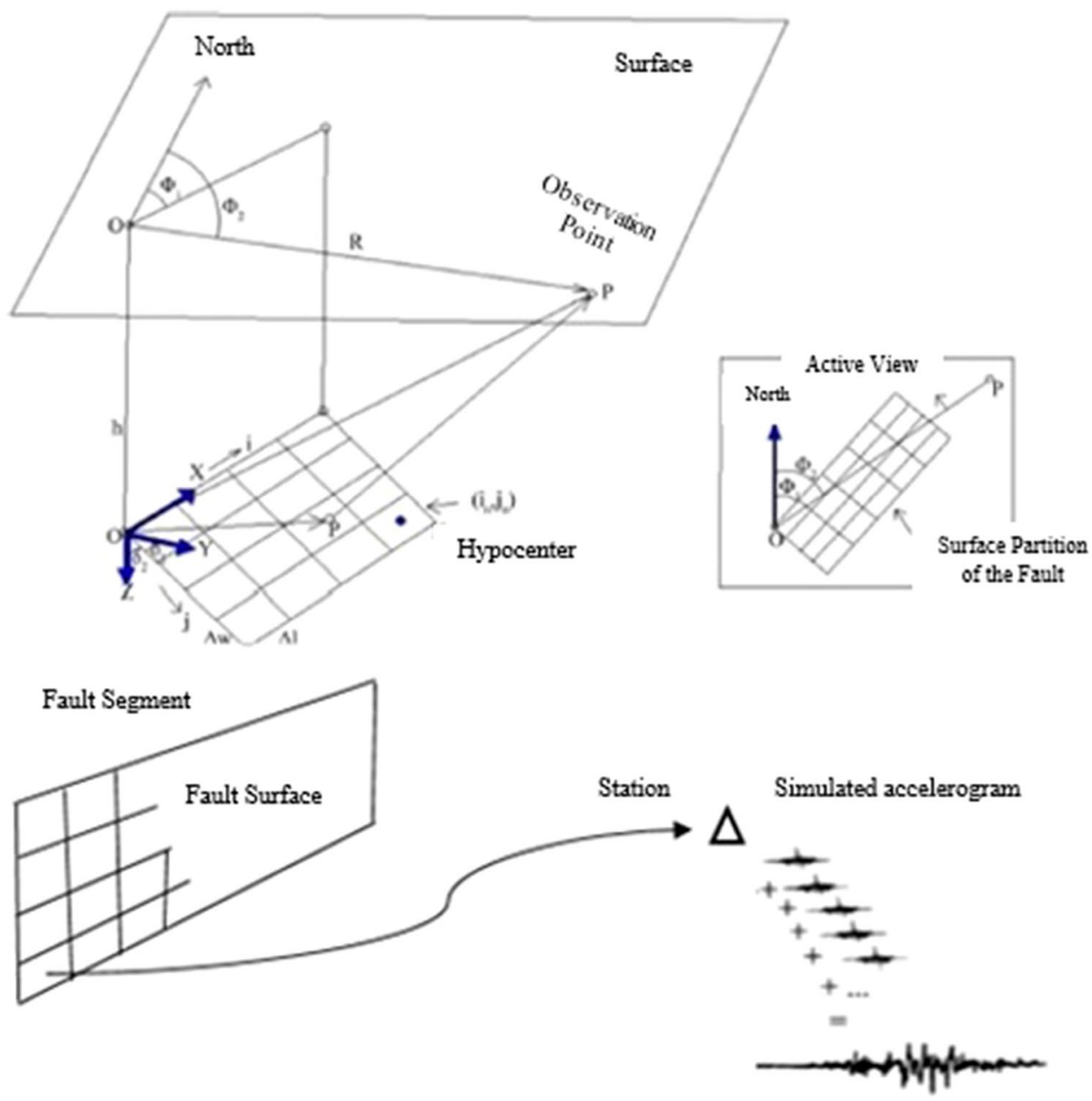

[34] introduced the new variety of this method based on the dynamic corner frequency. Their implementation had a significant advantage over previous algorithms such that it made the simulation results relatively insensitive to the sub-source size and thus eliminated the need for the multiple triggering of the sub-events [6]. Boore [12] further improved the algorithm with modifications to the sub-event normalization procedures that eliminated the remaining dependency on sub-source size and improved the treatment of low-frequency amplitudes. In this model, the corner frequency is a function of time, and the rupture history controls the frequency content of the simulated time series of each sub-fault. Moreover, the rupture begins with a high corner frequency and progresses to lower corner frequencies as the ruptured area grows. Additionally, limiting the number of active sub-faults in the calculation of dynamic corner frequency can control the amplitude of lower frequencies. In the revised EXSIM algorithm, Boore [12] properly normalized and delayed sub-source contributions, which are summed in the time domain as:
$A(t)=\sum_{i=1}^{N} H_{i} \times Y_{i}\left(t-\Delta t_{i}-T_{i}\right)$

$H_{i}=\frac{M_{0}}{M_{0_{i}}} \sqrt{\frac{\sum_{j}\left(\frac{f_{0}^{2} f_{i}}{f_{0}^{2}+f_{j}^{2}}\right)^{2}}{N \sum_{j}\left(\frac{f_{0_{i}}^{2} f_{i}}{f_{0_{i}}^{2}+f_{j}^{2}}\right)^{2}}}$

where $A(t)$ is the total seismic signal at the site, which incorporates the delays between the sub-sources. In addition, $H_{i}$ denotes a normalization factor for ith subsource that aims to conserve high-frequency amplitudes. Furthermore, $Y_{i}(t), N$, and $\Delta t_{i}$ indicate the signal of the ith sub-source (the inverse Fourier transform of the subsource spectrum), the total number of sub-sources, and the delay time of the sub-source, respectively. Additionally, $T_{i}$ and $M_{0}$ are a fraction of the rise time and the total seismic moment, respectively. Finally, $M_{0 i}$ displays the seismic moment of ith sub-source, which is internally calculated by the EXSIM based on the sub-source size $[5,6]$. The final 
version of the EXSIM, named "EXSIM12" by Atkinson and Assatourain [5], was used in the present research.

\subsection{Site response analysis}

Various evidence was reported regarding the site effect and nonlinear behavior of the local soil in previous earthquakes. The soil type and thus the dynamic characteristics of the soil profile (e.g., attenuation and shear modulus, moisture content, the number of layers, and their thickness) were all mentioned as factors that affect the nonlinear behavior of the soil $[17,18]$. Many researchers investigated the effects of different parameters on seismic magnification. For example, Hashash et al. [21, 22] and Rodriguez-Mark et al. [40] highlighted soil thickness as one of the most significant parameters for the seismic response. Pitilakiz et al. [38] also considered very high effects of different variables on seismic bedrock, including the soil type, soil classification and thickness, the dominant period of the local soil, and the average velocity of shear wave in the alluvial layer. It is noteworthy that the DEEPSOIL software, which is applied for site response analysis, was used for seismic magnification in the current study. DEEPSOIL is a unified one-dimensional program that is utilized for the dynamic analysis of the site response in linear, equivalent-linear, and nonlinear approaches. Moreover, this software provides the user with the required outputs by accelerograms and applying site conditions. The linear approach was utilized in this research as well. In this method, a conversion function with dynamic and force properties was determined based on one of the dynamic properties of the bedrock. This approach, which is based on the principle of force summation, is a very simple method based on complex number calculation. The bedrock motion, which is considered as accelerograms, can be converted to the Fourier series that can be further changed into the Fourier series of the ground motion of the used conversion function. Thus, the conversion function easily determines the resonance or damping of the bedrock motion when it arrives at the surface. After selecting the appropriate parameters for modeling in the study area, the simulation was conducted on the seismic bedrock surface based on the mentioned parameters. Figure 4 depicts the points of the simulation of strong ground motion. The PGA is estimated from the answer summing to obtain the results of the accelerogram and plot them based on acceleration and distance. Figure 5 shows a map of the chirp lines for the simulated maximum horizontal acceleration.

As depicted above, the peak horizontal acceleration produced by the northern fault of Tabriz reaches $0.80 \mathrm{~g}$ in the northern part of the city while the peak acceleration in the southern part decreases to $0.40 \mathrm{~g}$. Furthermore, the
584000591000598000605000612000619000626000633000640000

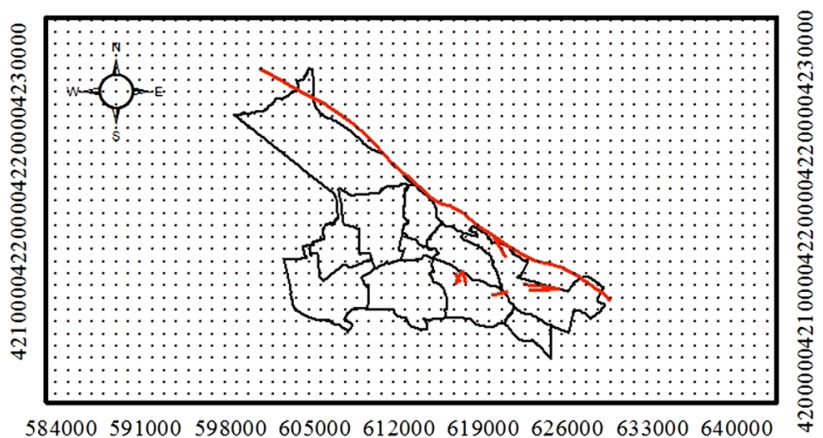

Fig. 4 The points of artificially produced accelerograms

massive losses and destructions are estimated in Tabriz because of the direct rupture hazard in the city, the fault in the urban area on Tabriz, and the effects of near-field fault in due time of the earthquake. There is a high potential for a landslide because of the marl-clay deposits in settlements such as Baghmisheh, Roshdieh, Eram, and Valiamr, at the northern part of Tabriz and near-field fault. Given that Tabriz Airport is located in the near-field fault, earthquakes can cause serious destructions, which could lead to the disruption of assistance at the time of a possible earthquake. After obtaining the seismic zonation of the target area, downhole data from different points of the urban area of Tabriz were gathered to assess the effect of soil stratification on the earthquake specification in terms of peak acceleration and frequency content. As shown in Fig. 6, data from all points of the target area are used to have good distribution. The DEEPSOIL software was used to determine the peak ground acceleration at the surface and to imply the amplification of the soil stratification effect. Accordingly, by having the seism frequency in different points of the area, the gathered geotechnical characteristics (e.g., the soil layer thickness, specific gravity, the shear wave velocity of the soil layer, and attenuation in different layers) were utilized as the input variables for the software. Finally, the magnitude and effect of seismic frequency traveling from soil layers were determined in different samples. After collecting and presenting the results within the target area, seismic zonation after reflection of the effect on the ground surface using the Arc map software is depicted in Fig. 7.

\subsection{Liquefaction potential in the study area}

Liquefaction occurs when vibrations or water pressure within the soil mass causes the particles to lose contact with each other. As a result, the soil behaves like a liquid fluid, is unable to withstand weight, and can flow on very gentle slopes. These conditions are usually temporary and 


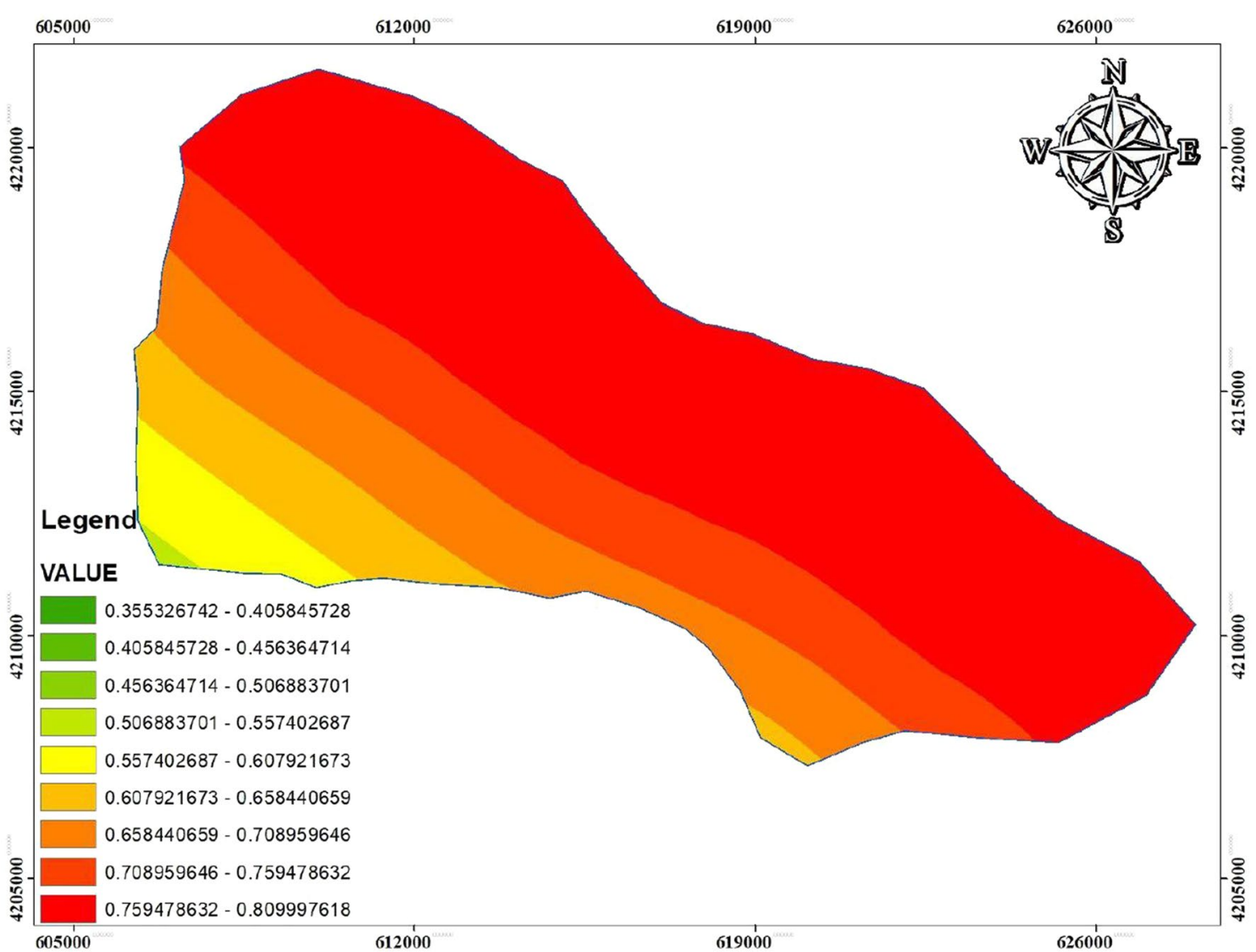

Fig. 5 The simulated horizontal maximum acceleration map in the study area

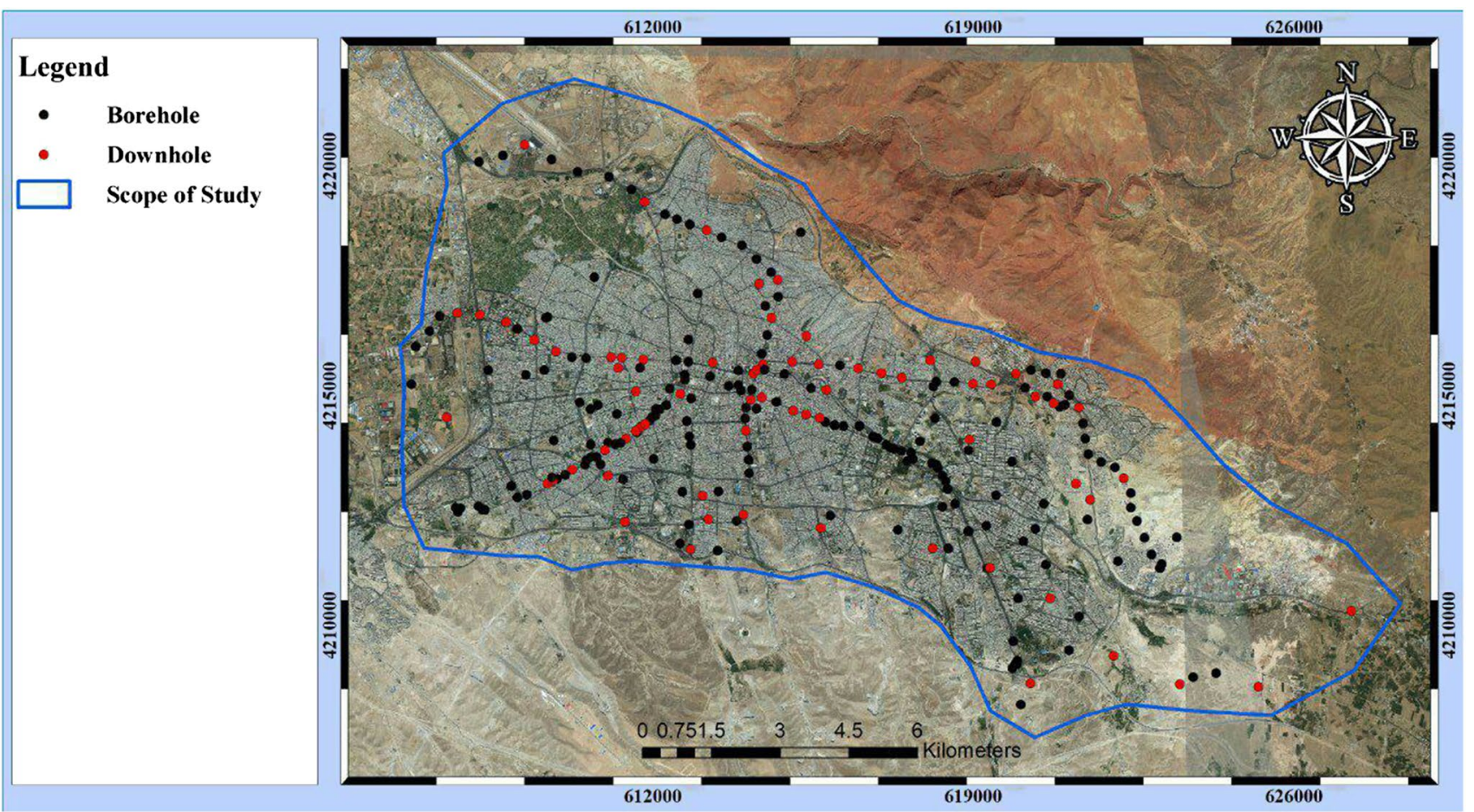

Fig. 6 Distribution of collected data for seismic amplification 


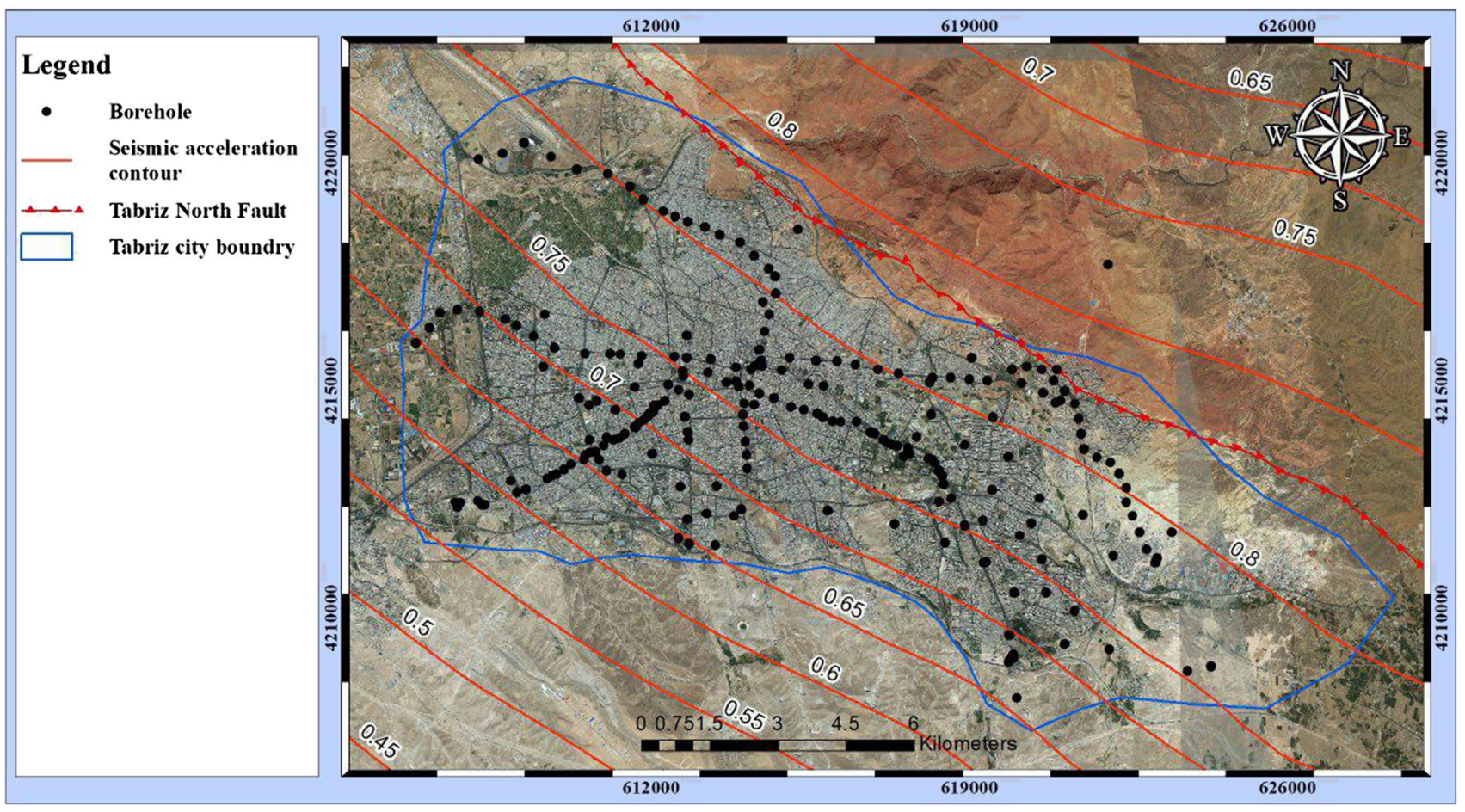

Fig. 7 The seismic zonation of Tabriz surface after amplification

often occur as a result of earthquakes in saturated bays of water or non-consolidated soils. Some of the important liquefaction effects were discovered in terms of the effects of the Kobe earthquakes in Japan (1995), Chi-Chi in Taiwan (1999), Bhoj in India (2001), and Fukushima in Japan (2011), which indicate these contents. Many structures that lie on the bed of saturated and loose soils are vulnerable to liquefaction. Soil liquefaction is one of the most complex phenomena to evaluate in geotechnical earthquake engineering. Many methods have been studied and evaluated over the years to evaluate the potential of liquefaction, the most common of which can be categorized into three sections, as schematically displayed in Fig. 8:

- Experimental or laboratory methods (intermittent stress, intermittent strain, and energy methods)

- Numerical methods (neural network, etc.)
Fig. 8 The most common evaluation methods of liquefaction

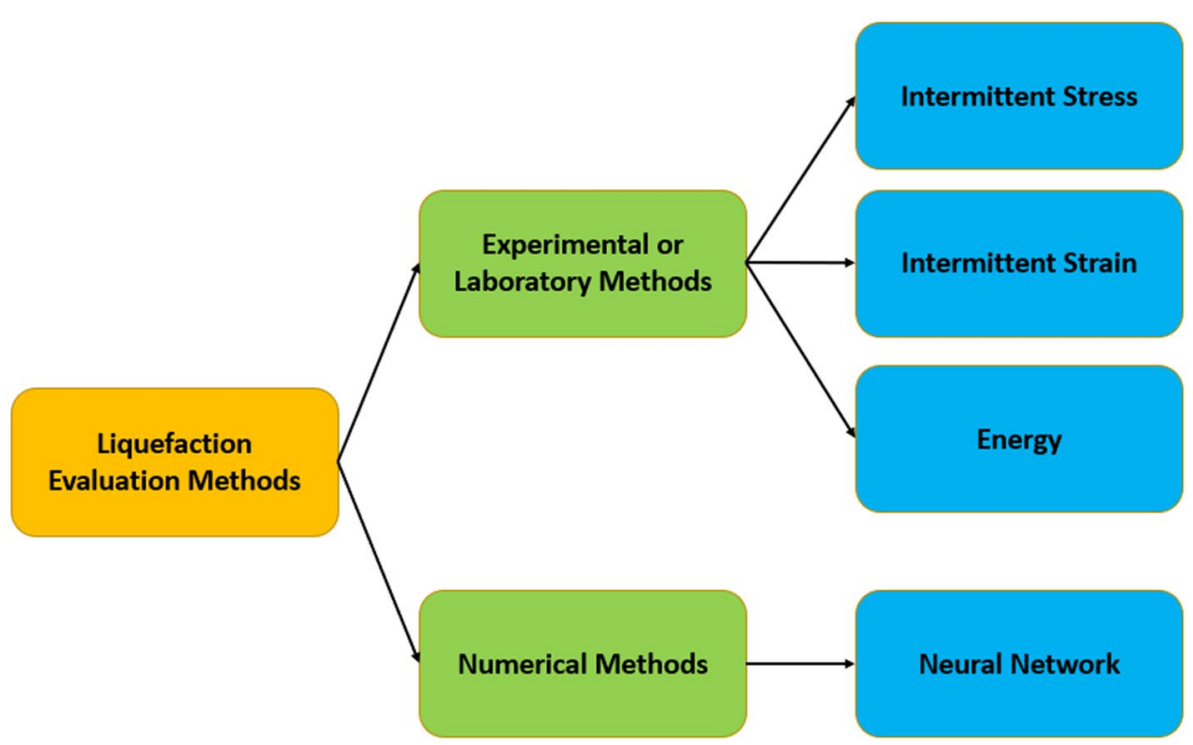


The intermittent stress method is the most common technique for evaluating liquefaction, which was presented by Seed and Idriss [42]. This method is mainly experimental and is based on laboratory and field observations. Seed et al. [43] proposed a method for estimating the liquefaction potential of grain soils based on standard penetration test (SPT) data. The scientist also presented an experimental version of Seed et al.'s [43] method to evaluate the liquefaction potential of silty sand and sandy soils by refining their previous method based on $\left(N_{1}\right)_{60}$, the SPT blow count normalized to an overburden pressure of approximately $100 \mathrm{kPa}$ ( $1 \mathrm{ton} / \mathrm{sq} \mathrm{ft}$ ) and a hammer energy ratio or hammer efficiency of $60 \%$, which affects the parameters of drilling rods, and ambient pressure provided another relationship. Cetin et al. [14] presented a new correlation based on SPT data to evaluate the possibility of soil liquefaction. These correlations eliminated several sources of deviation from the past and resulted in a significant reduction in uncertainty and overall dispersion. In this method, therefore, the overall uncertainty is further reduced compared to the one in previous methods. Sonmez [47] also provided additional factor-based (F.S) constraints for SPT and CPT data-based research. Sonmez and Gokceoglu [48] investigated and modified the structure of the liquefaction potential index (LPI) equation that was first classified by Iwasaki et al. [28, 29]. Since then, the liquefaction potential index has been studied by many researchers in different regions. Idriss and Boulanger [24] provided a comprehensive stress-based method to estimate the liquefaction potential via publishing a set of their research results. In this method, the value of cyclic stress ratio (CSR) is first estimated to express the rate of the severity of the earthquake load in an $M_{W}=7.5$, which is evaluated using Eq. (3):

$\mathrm{CSR}=0.65 \times \frac{a_{\max }}{g} \times \frac{\sigma_{V}}{\sigma_{V}^{\prime}} \times r_{d}$

where $a_{\max }$ is the peak ground acceleration, $g$ is the acceleration of gravity, $\sigma_{v}$ is total stress in the depth in the question, $\sigma^{\prime}{ }_{v}$ is effective stress in the same depth, and $r d$ is the shear stress reduction factor that accounts for the dynamic response of the soil profile, which is estimated using Eqs. 4, 5 , and 6 based on two parameters of depth $(Z)$ and earthquake magnitude (MW).

$r_{d}=\exp [\alpha(Z)+\beta(Z) * M]$

$\alpha(Z)=-1.012-1.126 * \sin \left(\frac{Z}{11.73}+5.133\right)$

$\beta(Z)=0.106-0.118 * \sin \left(\frac{Z}{11.28}+5.142\right)$
Second, a simplified and modified method proposed by Seed et al. [43] is used to determine the cyclic resistance ratio (CRR) of the soils. In this step, the results obtained from the standard penetration test are modified based on Eq. (7) proposed by Skempton [46] from Eq. (7). The values of parameters can be observed in Table 2 .

$\left(N_{1}\right)_{60}=N_{\mathrm{SPT}} \cdot C_{N} \cdot C_{E} \cdot C_{B} \cdot C_{R} \cdot C_{S}$

where $N_{\text {SPT }}$ is the number of standard penetration resistance test, $C_{N}, C_{E}, C_{S}, C_{B}$, and $C_{R}$ are the coefficients of the overburden stress, the hammer energy, the sampling method, the borehole diameter, and the rod length, respectively, and $\left(N_{1}\right)_{60}$ is the modified number of the SPT. After that, the value of $C_{N}$ is obtained from Eq. 8 as proposed by Idriss and Boulanger [24].

$C_{N}=\left(\frac{P_{a}}{\sigma_{V}^{\prime}}\right)^{m} \leq 1.7$

$m=0.784-0.0768 \sqrt{\left(N_{1}\right)_{60 C S}}$

where $P a=100 \mathrm{kPa}$ is the atmospheric pressure, $\sigma^{\prime}{ }_{V}$ is the effective stress at the depth in question, and $\left(N_{1}\right)_{60}$ modified the number of the SPT. An equivalent for the number of the SPT is determined in clean sand $\left(\left(N_{1}\right)_{60 \mathrm{CS}}\right)$ after its modification. According to the method of Idriss and Boulanger [24], the CRR is then assessed by the application of the following equations:

$\left(N_{1}\right)_{60 \mathrm{CS}}=\left(N_{1}\right)_{60}+\Delta\left(N_{1}\right)_{60}$

Table 2 Values of the correction coefficients of Eq. 5 [46]

\begin{tabular}{llll}
\hline Overburden pressure & Description & $C_{N}$ & $\left(P_{a} / \sigma_{v}^{\prime}\right)^{0.5}$ \\
& & $C_{N} \leq 1.7$ \\
\hline Energy ratio & Donut hammer & $C_{E}$ & $0.5-1.0$ \\
& Safety hammer & & $0.7-1.2$ \\
& Automatic-trip donut- & & $0.8-1.3$ \\
& type hammer & & \\
Borehole diameter & $65 \mathrm{~mm}-115 \mathrm{~mm}$ & $C_{B}$ & 1.0 \\
& $150 \mathrm{~mm}$ & & 1.05 \\
& $200 \mathrm{~mm}$ & & 1.15 \\
Rod length & $3 \mathrm{~m}-4 \mathrm{~m}$ & $C_{R}$ & 0.75 \\
& $4 \mathrm{~m}-6 \mathrm{~m}$ & & 0.85 \\
& $6 \mathrm{~m}-10 \mathrm{~m}$ & & 0.95 \\
& $10 \mathrm{~m}-30 \mathrm{~m}$ & & 1.0 \\
& $>30 \mathrm{~m}$ & & $<1.0$ \\
& Standard sampler & $C_{S}$ & 1.0 \\
Sampling method & Sampler without liners & & $1.1-1.3$ \\
& & &
\end{tabular}


where $\Delta\left(N_{1}\right)_{60}$ is a function of the percentage of fine grains in the soil (FC) as follows:

$\Delta\left(N_{1}\right)_{60}=\exp \left(1.63+\frac{9.7}{\mathrm{FC}+0.01}-\left(\frac{15.7}{\mathrm{FC}+0.01}\right)^{2}\right)$

\subsection{Liquefaction potential index (LPI)}

Researchers presented several methods for the assessment of the rate of liquefaction and the level of occurrence. One of the common methods was proposed by Iwasaki et al. $[28,29]$ presented in the following equations:

$\mathrm{CRR}_{M=7.5}=\exp \left(\left(\frac{\left(N_{1}\right)_{60 \mathrm{CS}}}{14.1}\right)+\left(\frac{\left(N_{1}\right)_{60 \mathrm{CS}}}{126}\right)^{2}-\left(\frac{\left(N_{1}\right)_{60 \mathrm{CS}}}{23.6}\right)^{3}-\left(\frac{\left(N_{1}\right)_{60 \mathrm{CS}}}{25.4}\right)^{4}-2.8\right)$

where $\mathrm{FC}$ is fines content in the soil layer. In the calculation of the CRR, if the amount of effective vertical stress at the depth in question is more than $100 \mathrm{kPa}$, the CRR value is modified by the following equation:

$$
\begin{aligned}
& \mathrm{CRR}_{\jmath}=\mathrm{CRR}_{M=7.5, \sigma_{V}^{\prime}=1} \times \mathrm{MSF} \times K_{\sigma} \\
& K_{\sigma}=\left[1-C_{\sigma} \times L_{n}\left(\frac{\sigma_{V}^{\prime}}{P_{a}}\right)\right] \leq 1.1 \\
& C_{\sigma}=\left[\frac{1}{18.9-2.55 \sqrt{\left(N_{1}\right)_{60 C S}}}\right] \leq 0.3
\end{aligned}
$$

where MSF (magnitude scale factor) is earthquake magnitude scale factor that is calculated based on Andrus and Stoke (1997) using Eq. 15.

MSF $=\left[6.9 \exp \left(\frac{-M w}{4}\right)-0.058\right] \leq 1.8$

$K_{\sigma}$ is the overburden correction factor, $\sigma^{\prime}{ }_{V}$ is the effective vertical stress, and $f$ is an exponent that is a function of site conditions, including relative density, stress history, aging, and the over-consolidation ratio. At last, the safety factor $(F s)$ against liquefaction in soil layers is calculated using Eq. (16):

$F_{\mathrm{S}}=\frac{\mathrm{CRR}_{j}}{\mathrm{CSR}}$

$$
\begin{aligned}
& \mathrm{LPI}=\int_{0}^{20} W(Z) \times F(Z) \cdot \mathrm{d} z \\
& F(Z)=1-F_{\mathrm{S}} \quad \text { For } F \mathrm{~s}<1 \\
& F(Z)=0 \quad \text { For } F \mathrm{~s} \geq 1 \\
& W(Z)=10-0.5 Z \quad \text { For } Z<20 \mathrm{~m} \\
& W(Z)=0 \quad \text { For } Z>20 \mathrm{~m}
\end{aligned}
$$

where $Z$ is the depth of midpoint in the layer of interest. The liquefaction intensity is stated between zero and 100 . The liquefaction risk can be obtained using Table 3 based on the LPI value.

For example, Fig. 9 shows the location of boreholes and soil layers based on the geological and groundwater data obtained from boreholes of the western part of tunnel route line 2 of the metro in Tabriz city. Geologically, this part of the tunnel comprises sedimentary rocks consisting of marls, claystone, siltstone, and sandstone, which are underlain by surface alluvium with a thickness of 5-15 m. In this part, the water table varies between 6 and $30 \mathrm{~m}$, and the consistency of the alluvium is classified as hard and very hard [33].

With the evaluation of 260 boreholes in the study area, the zoning map of the liquefaction potential index can be presented based on the method of Iwasaki et al. [29] according to Fig. 10. According to the results, the highest risk of liquefaction is limited to the southeastern regions of Tabriz. Also, a number of points with low liquefaction

Table 3 Liquefaction risk analysis based on the liquefaction potential index [28, 29]

\begin{tabular}{ll}
\hline $\mathrm{LPI}$ value & Liquefaction risk and investigation/countermeasures needed \\
\hline $\mathrm{LPI}=0$ & Liquefaction risk is very low. Detailed investigation is not generally needed. (very low) \\
$0<\mathrm{LPI} \leq 5$ & Liquefaction risk is low. Further detailed investigation is needed, especially for important structures. (low) \\
$5<\mathrm{LPI} \leq 15$ & $\begin{array}{l}\text { Liquefaction risk is high. Further detailed investigation is needed for structures. A countermeasure of } \\
\text { liquefaction is generally needed. (high) } \\
\mathrm{LPI}>15\end{array}$ \\
\hline
\end{tabular}




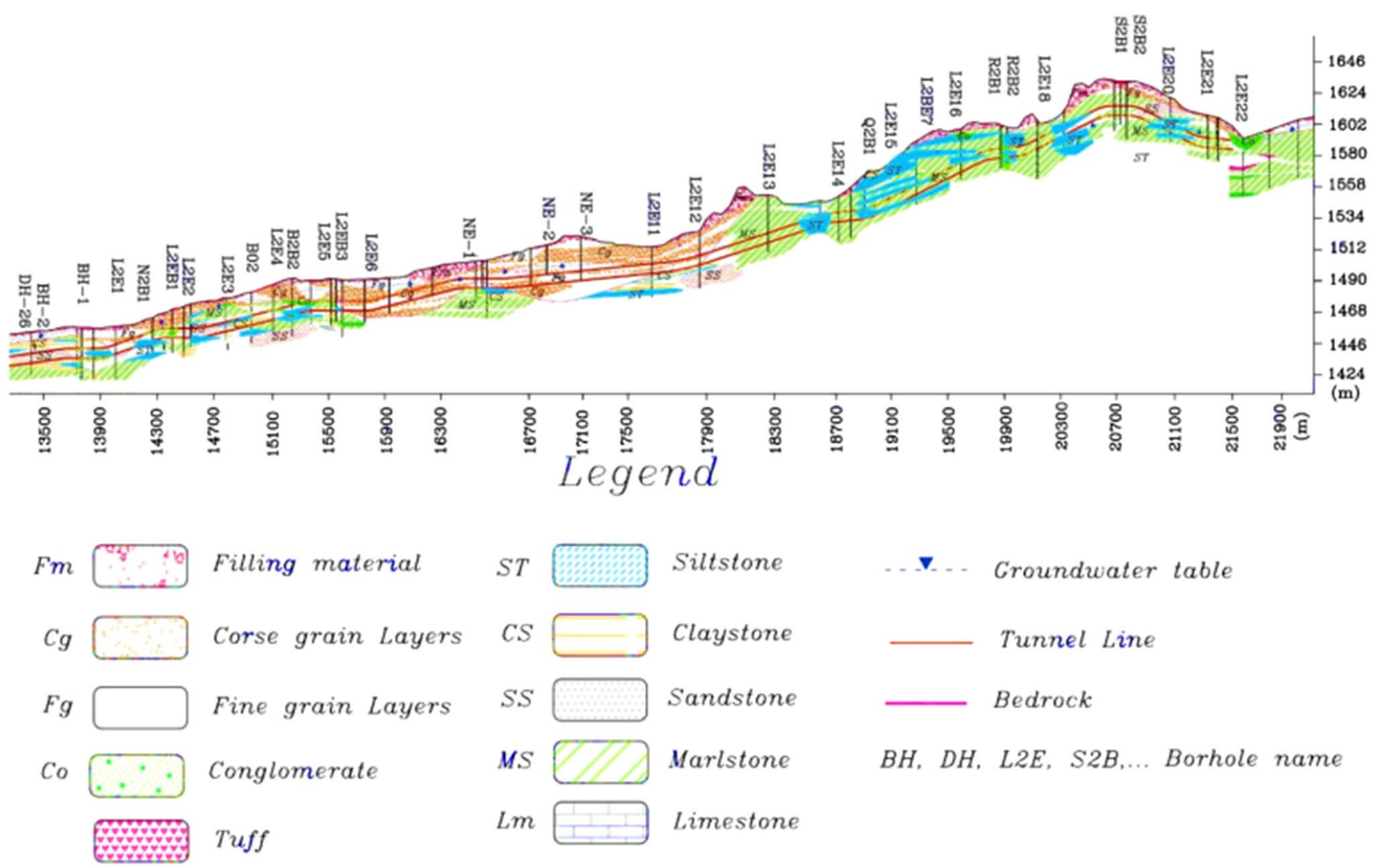

Fig. 9 Geotechnical section of the western part of tunnel route line 2 of the metro in Tabriz city [33]

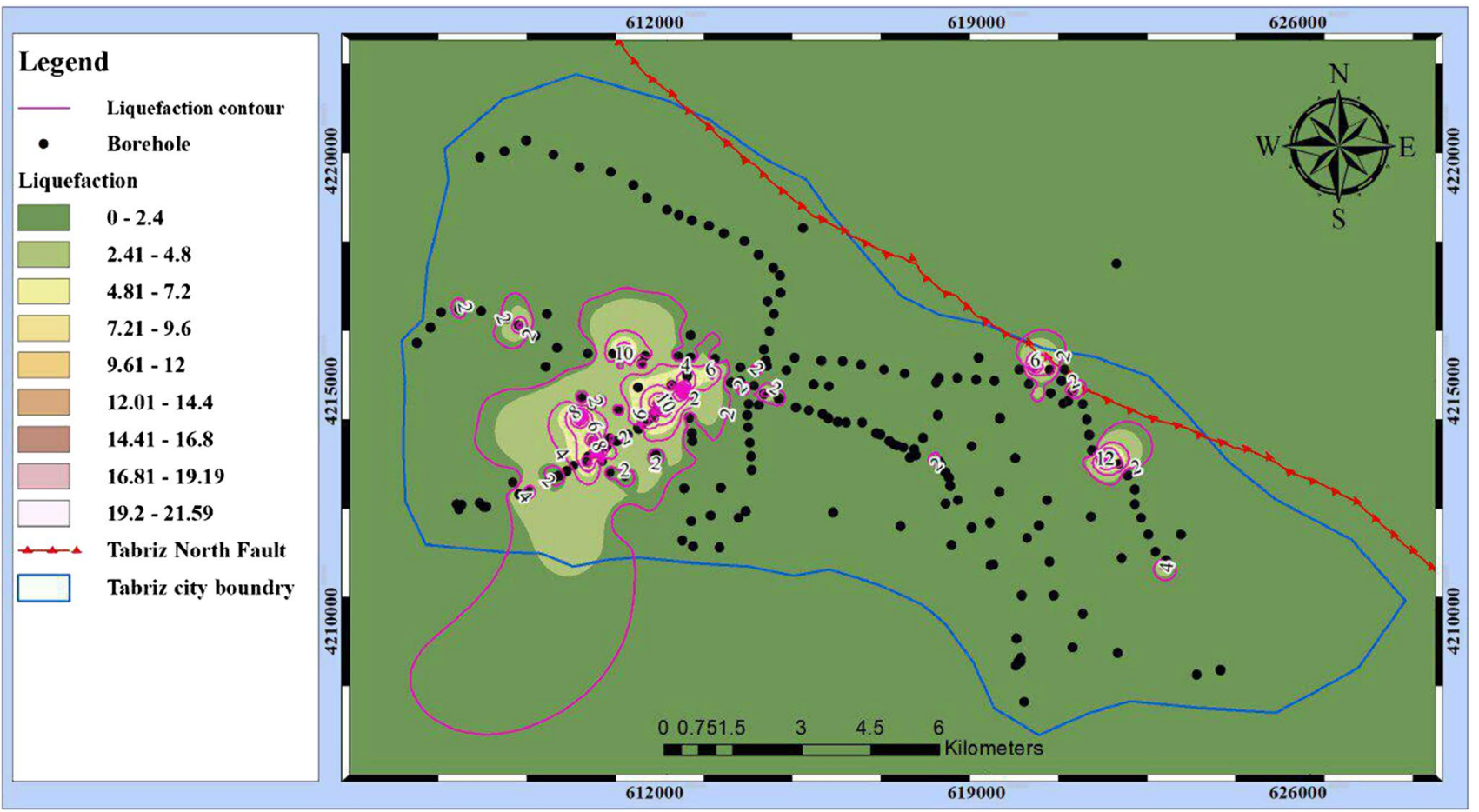

Fig. 10 Zoning map of liquefaction potential Index (LPI) in the study area based on Iwasaki et al. [29] 


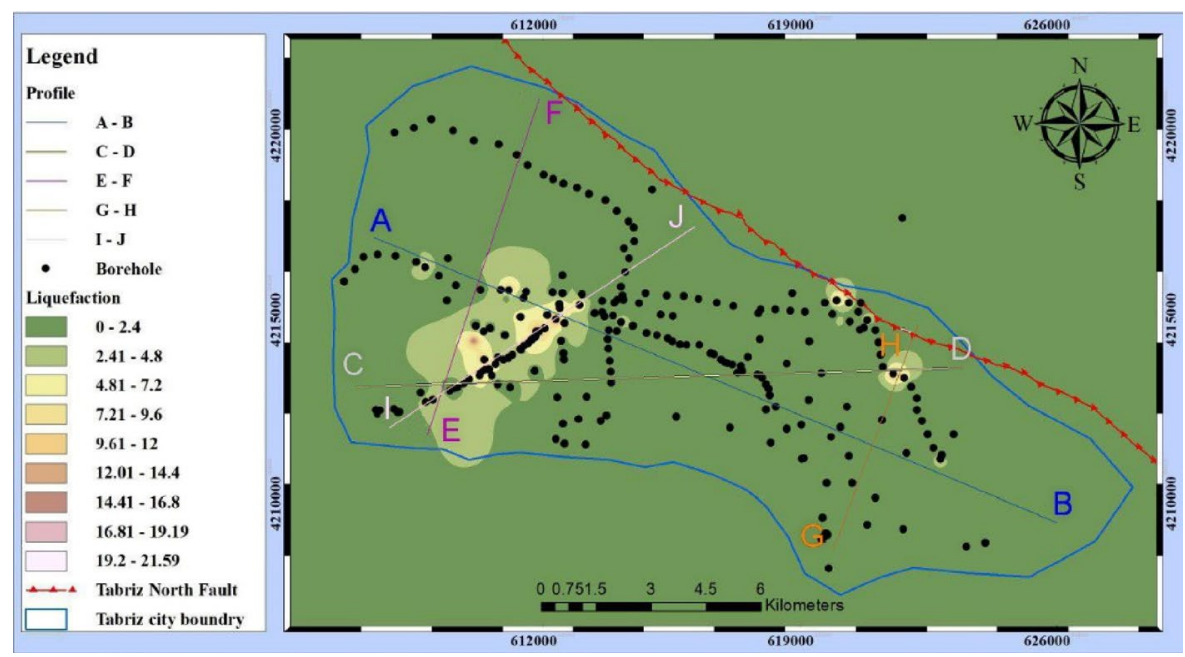

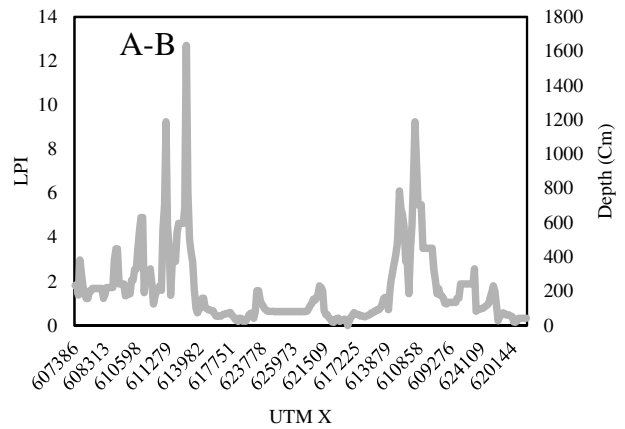

(a)

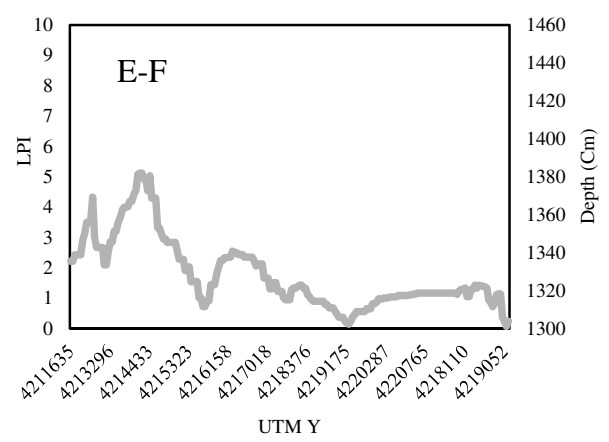

(c)

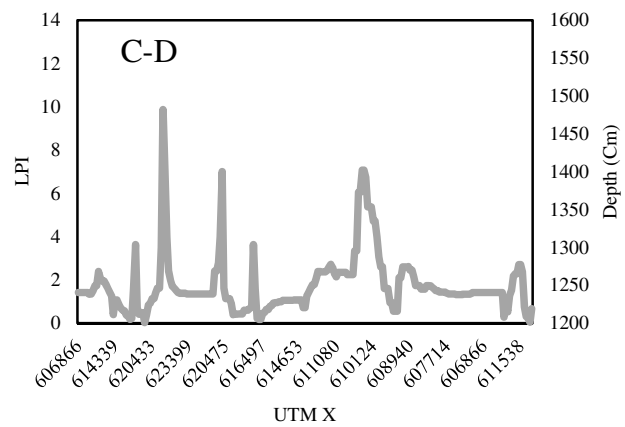

(b)

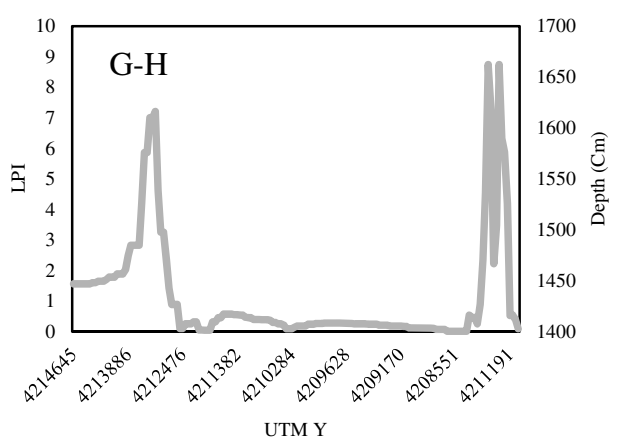

(d)

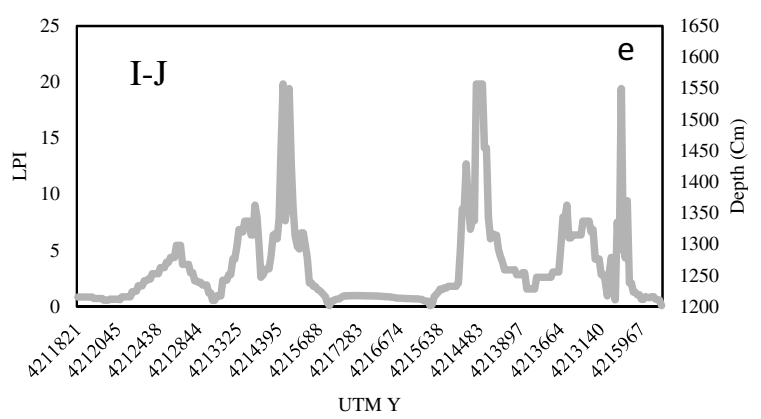

(e) 
4Fig. 11 Location of five axes in study area for evaluation of LPI in soil layers. Based on Iwasaki et al. [29] and variation of LPI in soil stratifications, a A-B axes, b C-D axes, c E-F axes, $\mathbf{d}$ G-H axes, e I-J axes

risk are observed in the soil stratifications in the northeastern regions of Tabriz due to the type of materials and groundwater level.

According to Fig. 11a-e, the highest risk of liquefaction is observed in the lower soil stratifications on the I-J axis. Also, according to Fig. 13 diagrams, risk index in the soil stratifications in the eastern part of Tabriz is the lowest. However, according to the liquefaction zoning curve, it can be seen that northeast of Tabriz has a minimum liquefaction risk.

\subsection{Data collection}

To estimate the soil liquefaction potential in different parts of the earth, there is a need for a scientific and numerical description of the resistance of different layers of the soil. Usually, laboratory and field methods are the best tools in this case. Although the laboratory results are usually better than the field ones, they usually use field results due to a wide range of factors. One of the methods widely used by researchers is the SPT. This test is one of the oldest and most extensive field geotechnical tests used to estimate the resistance of soil layers, which is considered an effective parameter in many other areas of geotechnics. Despite the disadvantages assigned to this test, the SPT test has three important advantages:

- The test provides an example of the soil in which the experiment was performed and thus determines the overall classification of the soil. Many penetration tests have a cone tip and do not have this capability. In these cases, soil classification can be derived solely on the basis of the correlation between the results of the experiment or through the results of boreholes and adjacent pits.

- The SPT is a fast and inexpensive test that is usually performed in a borehole drilled for other purposes, and thus, it does not impose any additional cost on the design.

- Almost all the test equipment is the same as used for drilling, and the proprietary equipment of this test is limited. However, other tests typically use extensive proprietary equipment.

In this study, the proposed equation by Idriss and Boulanger [24], which is a stress-based method, was used to estimate the liquefaction potential. This method requires the geotechnical description of the subsurface layers, such as the amount of resistance, the groundwater level, the percentage of fines content, the type of soil, and the thickness of the layers. Therefore, to describe the potential of liquefaction at a regional level, valid data were collected from exploratory boreholes. The scope of the study is displayed in Fig. 1. For this purpose, 260 out of 446 boreholes containing complete and descriptive data were selected here. The position of these boreholes with the curves of PGA values is presented in Fig. 12. The calculation of the liquefaction potential in soil layers revealed that there were 63 boreholes with liquefaction risks. The summarized data in Table 4 show that $\mathrm{H}$ represents the maximum depth of the soil levels, SPT shows the SPT value, $\left(N_{1}\right)_{60 c s}$ is the modified penetration number equivalent to clean sand, FC stands for fines content percentage in soil, TC is the depth of the soil layer, $A$ is the ground acceleration of the soil, and W.L represents the maximum water level in meter. The results indicate that there is a likelihood of liquefaction in 100 boreholes in the area. These data are utilized to train an ANN to numerically predict the liquefaction potential.

\section{Artificial neural network}

An ANN is an idea for processing information, which is inspired by the biological nervous system and processes information similar to the brain. A key element of this idea is the new structure of the information processing system, consisting of a large number of highly interconnected processing elements called neurons that work together to solve a problem. Similar to humans, ANNs learn by example, and a neural network is set up to perform specific tasks, such as identifying patterns and categorizing information, during a learning process. In biological systems, learning is accompanied by adjustments in the synaptic connections between the nerves. This method is also used in neural networks. ANNs transfer the knowledge or rule behind the data to the network structure by processing experimental data, which is called learning. The ability to learn is essentially the most important feature of an intelligent system. A system capable of learning is more flexible, easier to program, and can be better responsive to new problems and equations. The neural network structure of humans has long been sought to understand the biophysiology of the brain. In fact, it has always been interesting for humans to be intelligent, capable of generalization, creativity, flexibility, and parallel processing in the brain and use these capabilities in machines very well. Algorithmic methods are not suitable for the implementation of these properties in machines, and thus, the methods must be devised based on the same biological models. In other words, the neural network is a data processing system 


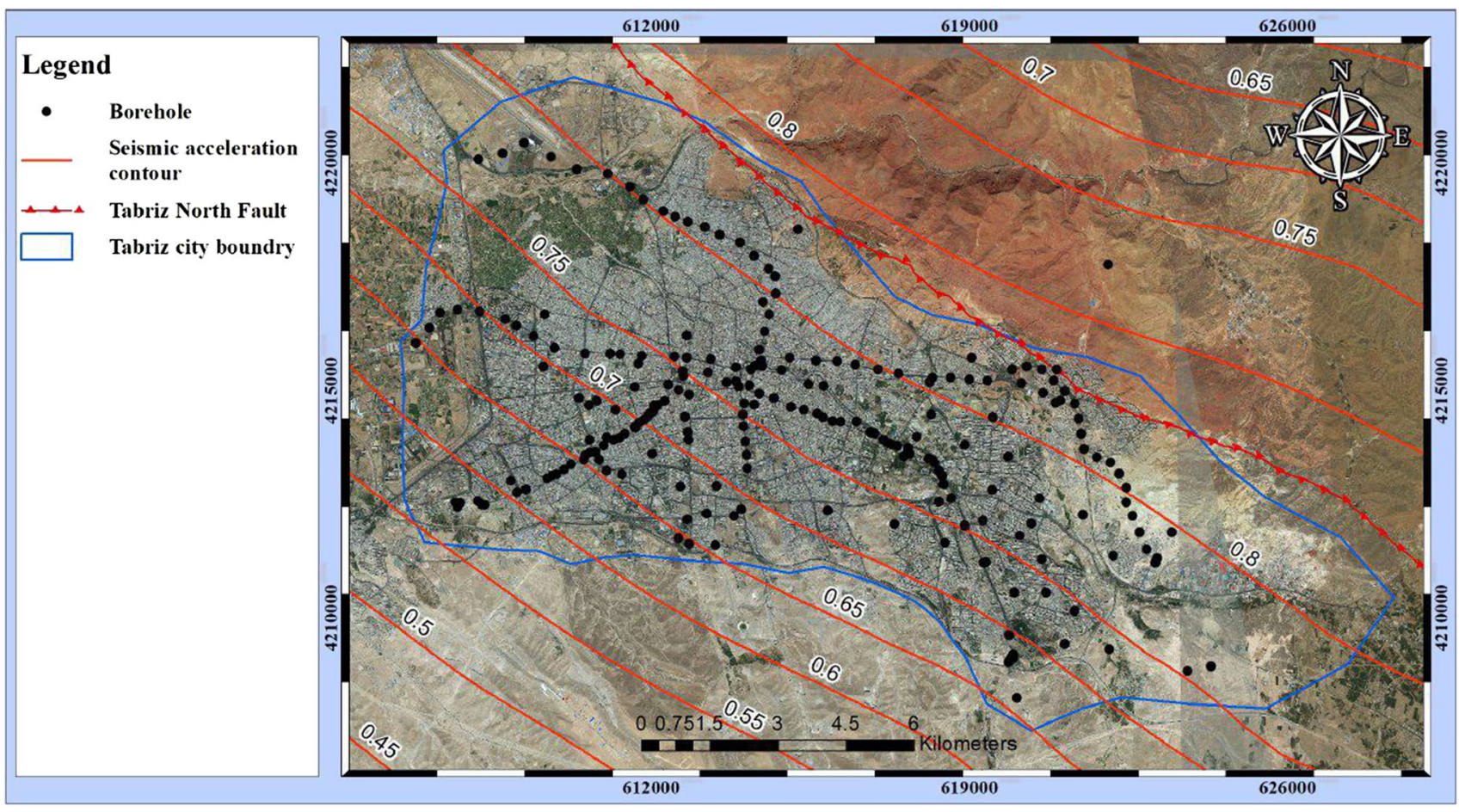

Fig. 12 The positions of the boreholes with curves of PGA values in the study area

that originates from the human brain and leaves the data processing to large multiple processors that operate in a networked and parallel way to solve a problem. Using programming knowledge in these networks, a data structure is designed that can act as a neuron called a node. In this structure, the network is trained through creating a network between these nodes and applying a training algorithm inside. In this memory or neural network, the nodes have two active (on) and inactive (off) states, and each edge (synapse or linkage between nodes) has a weight. Positive-weight edges stimulate or activate the next inactive node, and negative-weight edges inactivate or inhibit the next connected node (if active). The general configuration of neurons is depicted in Fig. 13.

\subsection{ANN configurations}

As it is known from the literature, a usual kind of neural network includes tens, hundreds, thousands, or even millions of artificial neurons in a single group of layers, which are interconnected with the rest of the layers that are famous as input units. The considered units are configured to receive various forms of information from the outside world that the network seeks to be trained, recognize, and do processes. Some of the other parts, called output units, are on the opposite part of the network and identify the network reaction to the information achieved. Among the input and output units, there are secret units that come together from the majority of the artificial brains. These neural networks are completely joined, meaning that each hidden and output unit is attached to layer units on each side. The connection of these units is satisfied by a number called weight. Weights are almost positive (if one unit triggers another unit) or even negative (if one unit suppresses or inhibits another unit). The higher the weight is, the greater the effect of one unit on another would be. This is known to the way in which real brain cells stimulate each other in tiny fissures, called synapses. Various kinds of ANNs have been proposed, each of which has a specific application. One of the most basic available neural models is the multilayer perceptron (MLP) model that simulates the transient function of the human knowledge and brain. Most of the network behavior in these types of neural networks have been taken into account in the human brain and its signal propagation and hence are sometimes referred to as feedforward networks. Every neuron in the human brain processes the input after receiving it (from one neuronal or non-neuronal cell) and sends the result to another (neuronal or non-neuronal) cell. This kind of behavior continues until reaching a definite result, which may eventually lead to a decision, process, thought, or move. The general configuration of an MLP is depicted in Fig. 14. As with the MLP neural network paradigm, there is another kind of neural network in which processor units are process-focused in a particular location. This focus is modeled through radial basis functions (RBFs). Regarding 
Table 4 Characteristics of the boreholes

\begin{tabular}{|c|c|c|c|c|c|c|c|c|c|}
\hline No. & ID & $H(\mathrm{~m})$ & $\mathrm{SPT}^{*}$ & $\left(N_{1}\right)_{60 C S}$ & FC (\%) & $\mathrm{TC}(\mathrm{m})$ & $A(\mathrm{~g})$ & W.L (m) & LPI \\
\hline 1 & $\mathrm{BH}-3$ & 18 & 34 & 24.3 & 20 & 5 & 0.770039 & 15 & 3 \\
\hline 2 & $\mathrm{BH}-4$ & 14 & 35 & 25.91 & 12 & 6 & 0.606295 & 12.2 & 3.51 \\
\hline 3 & $\mathrm{BH}-6$ & 18 & 41 & 34.41 & 17 & 2 & 0.76515 & 18 & 0 \\
\hline 4 & $\mathrm{BH}-7$ & 17 & 40 & 30.58 & 22 & 2 & 0.765404 & 13 & 0 \\
\hline 5 & $\mathrm{BH}-8$ & 15 & 41 & 31.08 & 20 & 6 & 0.734967 & 13 & 0 \\
\hline 6 & $\mathrm{BH}-9$ & 9 & 28 & 21.64 & 17 & 9 & 0.75096 & 8 & 15.68 \\
\hline 7 & $\mathrm{BH}-10$ & 17 & 30 & 22.77 & 18 & 12 & 0.699403 & 8.5 & 16.2 \\
\hline 8 & $\mathrm{BH}-12$ & 18 & 63 & 51.18 & 67 & 0 & 0.777571 & 20.5 & 0 \\
\hline 9 & $\mathrm{BH}-13$ & 18 & 17 & 12.68 & 15 & 11 & 0.66124 & 9 & 17.2 \\
\hline 10 & $\mathrm{BH}-14$ & 17 & 19 & 16.57 & 19 & 12 & 0.67764 & 4 & 17.5 \\
\hline 11 & $\mathrm{BH}-15$ & 16 & 23 & 20.53 & 21 & 10 & 0.665365 & 3 & 13.56 \\
\hline 12 & $\mathrm{BH}-16$ & 16 & 32 & 25.36 & 15 & 9 & 0.715936 & 5.5 & 14.5 \\
\hline 13 & BH-18 & 16 & 30 & 22.43 & 18 & 6 & 0.773174 & 11 & 6.5 \\
\hline 14 & BH-19 & 9 & 43 & 43.82 & 56 & 7 & 0.77417 & 5 & 0 \\
\hline 15 & $\mathrm{BH}-20$ & 14 & 44 & 42.79 & 55 & 15 & 0.772921 & 5 & 0 \\
\hline 16 & $\mathrm{BH}-21$ & 16 & 60 & 54.71 & 57 & 8 & 0.777571 & 4 & 0 \\
\hline 17 & $\mathrm{BH}-22$ & 13 & 52 & 49.86 & 57 & 7 & 0.770611 & 5 & 0 \\
\hline 18 & $\mathrm{BH}-23$ & 5 & 20 & 25.56 & 58 & 2 & 0.778735 & 3.3 & 6 \\
\hline 19 & $\mathrm{BH}-31$ & 18 & 21 & 15.15 & 17 & 7 & 0.767864 & 12.9 & 6.3 \\
\hline 20 & $\mathrm{BH}-32$ & 17 & 18 & 12.05 & 12 & 4 & 0.763633 & 10.3 & 4.5 \\
\hline 21 & BH-41 & 18 & 65 & 52.73 & 68 & 6 & 0.777406 & 14 & 0 \\
\hline 22 & BH-42 & 9 & 65 & 53.43 & 5 & 3 & 0.776461 & 8 & 0 \\
\hline 23 & $\mathrm{BH}-45$ & 19 & 25 & 19.74 & 15 & 2 & 0.686902 & 17.2 & 2.5 \\
\hline 24 & BH-46 & 19 & 35 & 32.12 & 17 & 4 & 0.676065 & 15.9 & 0.75 \\
\hline 25 & $\mathrm{BH}-47$ & 18 & 32 & 31.09 & 20 & 4 & 0.662431 & 14.8 & 0.75 \\
\hline 26 & $\mathrm{BH}-48$ & 18 & 35 & 25.19 & 15 & 4 & 0.646018 & 12.8 & 1 \\
\hline 27 & BH-49 & 13 & 30 & 25.09 & 67 & 0 & 0.808041 & 5 & 0 \\
\hline 28 & $\mathrm{BH}-50$ & 12 & 60 & 56.52 & 23 & 3 & 0.807043 & 3 & 0 \\
\hline 29 & BH-51 & 16 & 43 & 32.26 & 43 & 4 & 0.805747 & 14 & 0 \\
\hline 30 & $\mathrm{BH}-52$ & 14 & 80 & 70.87 & 26 & 4 & 0.805455 & 9 & 0 \\
\hline 31 & $\mathrm{BH}-54$ & 13 & 80 & 74.01 & 28 & 7 & 0.800066 & 4 & 0 \\
\hline 32 & BH-60 & 13 & 45 & 38.83 & 20 & 10 & 0.779652 & 5 & 0 \\
\hline 33 & $\mathrm{BH}-62$ & 12 & 63 & 57.66 & 55 & 3 & 0.77076 & 9 & 0 \\
\hline 34 & $\mathrm{BH}-63$ & 13 & 22 & 20.59 & 22 & 5 & 0.760607 & 8.7 & 9.6 \\
\hline 35 & BH-66 & 12 & 34 & 28.44 & 17 & 5 & 0.742972 & 7.5 & 4.64 \\
\hline 36 & BH-67 & 10 & 8 & 14.13 & 22 & 18 & 0.733534 & 8 & 14.8 \\
\hline 37 & BH-68 & 8 & 27 & 26.29 & 65 & 3 & 0.729692 & 7 & 3.97 \\
\hline 38 & BH-70 & 20 & 45 & 33.48 & 12 & 2 & 0.70976 & 10 & 0 \\
\hline 39 & BH-71 & 17 & 48 & 42.3 & 63 & 4 & 0.71026 & 13 & 0 \\
\hline 40 & $\mathrm{BH}-72$ & 14 & 34 & 25.64 & 25 & 2 & 0.709273 & 12.4 & 7 \\
\hline 41 & BH-73 & 14 & 23 & 22.61 & 58 & 1 & 0.707362 & 14 & 1.81 \\
\hline 42 & BH-79 & 14 & 40 & 33.82 & 56 & 6 & 0.809254 & 8 & 0 \\
\hline 43 & $\mathrm{BH}-80$ & 12 & 26 & 24.8 & 48 & 6 & 0.809698 & 5 & 12.58 \\
\hline 44 & BH-81 & 16 & 18 & 16 & 43 & 4 & 0.809221 & 11.8 & 6.08 \\
\hline 45 & $\mathrm{BH}-82$ & 14 & 45 & 37.4 & 56 & 6 & 0.808932 & 9 & 0 \\
\hline 46 & $\mathrm{BH}-83$ & 12 & 32 & 27.7 & 43 & 4 & 0.808678 & 9.7 & 6.03 \\
\hline 47 & $\mathrm{BH}-85$ & 11 & 34 & 30.58 & 36 & 3 & 0.807064 & 8.1 & 1.12 \\
\hline 48 & BH-88 & 11 & 23 & 20.92 & 54 & 10 & 0.80315 & 5.7 & 16.02 \\
\hline 49 & BH-89 & 6 & 24 & 26.28 & 70 & 3 & 0.803842 & 4.7 & 7 \\
\hline 50 & $\mathrm{BH}-90$ & 9 & 39 & 36.26 & 65 & 4 & 0.808932 & 7 & 0 \\
\hline 51 & BH-97 & 9 & 29 & 27.18 & 75 & 3 & 0.787928 & 8 & 5.3 \\
\hline
\end{tabular}


Table 4 (continued)

\begin{tabular}{|c|c|c|c|c|c|c|c|c|c|}
\hline No. & ID & $H(\mathrm{~m})$ & $\mathrm{SPT}^{*}$ & $\left(N_{1}\right)_{60 \mathrm{CS}}$ & FC (\%) & $\mathrm{TC}(\mathrm{m})$ & $A(\mathrm{~g})$ & W.L (m) & LPI \\
\hline 52 & $\mathrm{BH}-100$ & 19 & 10 & 8.41 & 17 & 2 & 0.800932 & 17 & 0.66 \\
\hline 53 & $\mathrm{BH}-103$ & 19 & 63 & 50.01 & 85 & 0 & 0.803655 & 16 & 0 \\
\hline 54 & $\mathrm{BH}-110$ & 19 & 48 & 35.28 & 53 & 2 & 0.796002 & 17 & 0 \\
\hline 55 & $\mathrm{BH}-120$ & 25 & 32 & 24.36 & 16 & 0 & 0.724682 & 24 & 0 \\
\hline 56 & $\mathrm{BH}-133$ & 17 & 68 & 56.11 & 16 & 7 & 0.800117 & 9 & 0 \\
\hline 57 & $\mathrm{BH}-134$ & 17 & 34 & 25.22 & 26 & 6 & 0.707007 & 13 & 4.63 \\
\hline 58 & $\mathrm{BH}-135$ & 16 & 35 & 29.32 & 41 & 3 & 0.735596 & 14 & 2 \\
\hline 59 & $\mathrm{BH}-140$ & 16 & 55 & 39.12 & 28 & 4 & 0.723141 & 14 & 0 \\
\hline 60 & $\mathrm{BH}-142$ & 15 & 30 & 25.11 & 32 & 5 & 0.720273 & 10.2 & 6 \\
\hline 61 & BH-143 & 16 & 47 & 37.56 & 44 & 6 & 0.67713 & 11 & 0 \\
\hline 62 & $\mathrm{BH}-146$ & 15 & 42 & 30.49 & 12 & 6 & 0.687882 & 9 & 4 \\
\hline 63 & $\mathrm{BH}-150$ & 13 & 42 & 32.45 & 21 & 2 & 0.694063 & 11 & 0 \\
\hline 64 & BH-156 & 21 & 52 & 46.28 & 26 & 0 & 0.715488 & 22 & 0 \\
\hline 65 & $\mathrm{BH}-157$ & 19 & 49 & 35.78 & 49 & 4 & 0.718803 & 16 & 0 \\
\hline 66 & $\mathrm{BH}-160$ & 21 & 68 & 54.29 & 55 & 0 & 0.792063 & 10 & 0 \\
\hline 67 & $\mathrm{BH}-170$ & 15 & 27 & 16.72 & 5 & 5 & 0.712593 & 11 & 9.6 \\
\hline 68 & $\mathrm{BH}-178$ & 17 & 85 & 65.65 & 14 & 5 & 0.65729 & 12 & 0 \\
\hline 69 & BH-188 & 15 & 73 & 63.02 & 85 & 2 & 0.78803 & 13 & 0 \\
\hline 70 & BH-198 & 18 & 37 & 26.51 & 22 & 4 & 0.770039 & 15 & 2 \\
\hline 71 & BH-199 & 16 & 13 & 14.53 & 32 & 5 & 0.75096 & 8 & 8.1 \\
\hline 72 & $\mathrm{BH}-200$ & 16 & 29 & 22.17 & 17 & 7 & 0.699403 & 8.5 & 11.5 \\
\hline 73 & BH-201 & 15 & 15 & 14.02 & 25 & 4 & 0.66124 & 9 & 9 \\
\hline 74 & BH-206 & 13 & 30 & 23.95 & 18 & 3 & 0.613237 & 11.5 & 5.5 \\
\hline 75 & BH-207 & 13 & 34 & 29.3 & 21 & 4 & 0.627186 & 22 & 2.3 \\
\hline 76 & $\mathrm{BH}-208$ & 12 & 32 & 27.98 & 17 & 3 & 0.643181 & 9 & 4.5 \\
\hline 77 & BH-209 & 12 & 27 & 23.44 & 21 & 3 & 0.668715 & 5.4 & 6.6 \\
\hline \multirow[t]{2}{*}{78} & $\mathrm{BH}-211$ & 11 & 22 & 27.66 & 42 & 5 & 0.748223 & 6.2 & 8.3 \\
\hline & $\mathrm{BH}-212$ & 13 & 18 & 17.84 & 36 & 9 & 0.73701 & 5.5 & 25 \\
\hline 80 & $\mathrm{BH}-213$ & 14 & 26 & 25.71 & 24 & 4 & 0.72377 & 6.8 & 5.6 \\
\hline 81 & BH-214 & 7 & 17 & 16.77 & 34 & 10 & 0.718195 & 4.1 & 25.2 \\
\hline 82 & BH-215 & 9 & 32 & 30.2 & 30 & 2 & 0.710365 & 4.6 & 1.25 \\
\hline 83 & $\mathrm{BH}-216$ & 8 & 23 & 23.98 & 23 & 4 & 0.70151 & 4.7 & 10.5 \\
\hline 84 & $\mathrm{BH}-221$ & 9 & 29 & 28.23 & 37 & 3 & 0.694063 & 7.8 & 2.6 \\
\hline 85 & BH-222 & 10 & 30 & 30.05 & 41 & 3 & 0.686672 & 7.2 & 1.6 \\
\hline 86 & $\mathrm{BH}-223$ & 10 & 27 & 30.15 & 30 & 2 & 0.681405 & 7.2 & 1 \\
\hline 87 & BH-224 & 9 & 31 & 29.13 & 34 & 2 & 0.676146 & 6.6 & 2.8 \\
\hline 88 & BH-225 & 10 & 34 & 30.85 & 28 & 5 & 0.659048 & 7.8 & 1 \\
\hline 89 & $\mathrm{BH}-226$ & 9 & 23 & 23.25 & 27 & 3 & 0.653714 & 7.1 & 8.6 \\
\hline 90 & BH-227 & 13 & 23 & 21.94 & 32 & 8 & 0.650598 & 5.8 & 13.3 \\
\hline 91 & BH-228 & 17 & 25 & 19.89 & 29 & 3 & 0.636206 & 14 & 2.63 \\
\hline 92 & BH-229 & 16 & 32 & 30.11 & 30 & 2 & 0.634185 & 19.6 & 1 \\
\hline 93 & $\mathrm{BH}-231$ & 16 & 32 & 30.04 & 41 & 3 & 0.62922 & 22 & 1 \\
\hline 94 & $\mathrm{BH}-232$ & 15 & 34 & 29.33 & 28 & 2 & 0.623978 & 14 & 2 \\
\hline 95 & $\mathrm{BH}-234$ & 9 & 28 & 28.05 & 32 & 3 & 0.653762 & 12 & 4 \\
\hline 96 & BH-242 & 11 & 22 & 29.9 & 16 & 2 & 0.762503 & 12 & 1.5 \\
\hline 97 & $\mathrm{BH}-243$ & 12 & 30 & 26.55 & 44 & 3 & 0.807866 & 7 & 3.6 \\
\hline 98 & $\mathrm{BH}-244$ & 21 & 64 & 58.23 & 66 & 0 & 0.788136 & 15 & 0 \\
\hline 99 & $\mathrm{BH}-249$ & 19 & 38 & 29.93 & 38 & 4 & 0.7831 & 16 & 2.3 \\
\hline 100 & BH-254 & 21 & 21 & 16.87 & 86 & 0 & 0.523 & 16 & 0 \\
\hline
\end{tabular}

*The provided SPT is for the soil layer with a higher possibility of liquefaction (with larger SPT values), and the other parameters are related to the selected SPT 


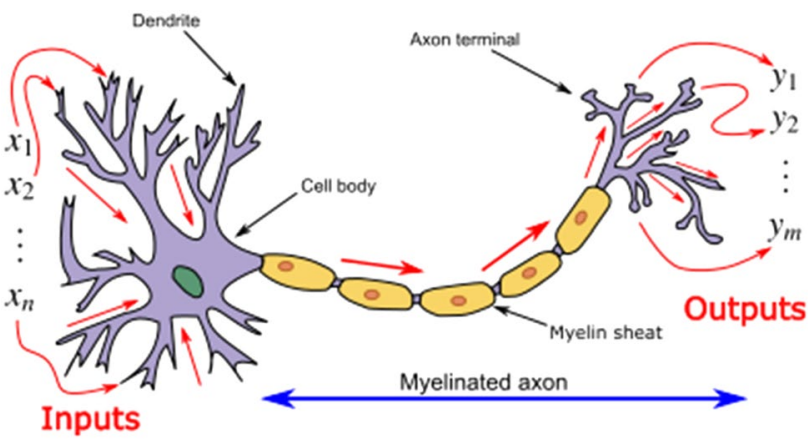

Fig. 13 The general configuration of neurons

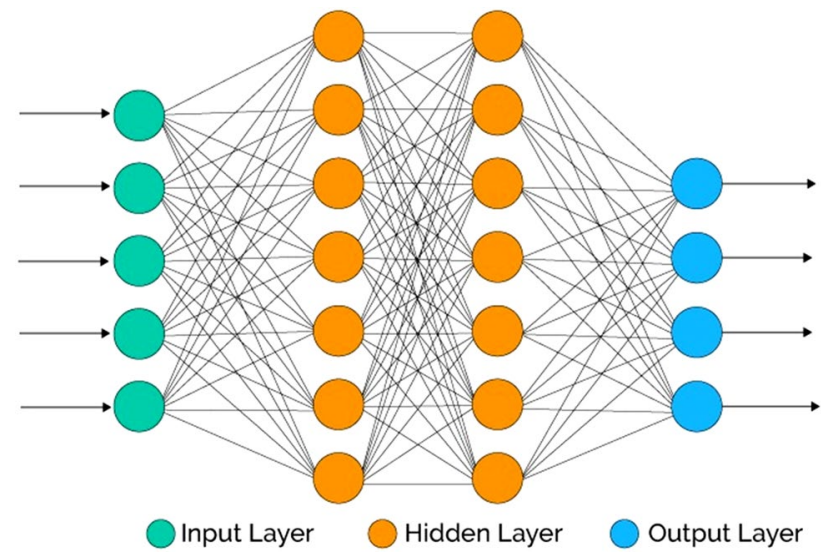

Fig. 14 The general configuration of an MLP

the overall structure, RBF neural networks are not much different from MLP networks and are merely the type of processing that neurons perform on their inputs. Meanwhile, RBF networks often have a faster learning and preparation process. Since the neurons focus on a specific functional range, they are easier to adjust. The general configuration of an RBF is depicted in Fig. 15. In MLP and RBF neural networks, the focus is often on enhancing the neural network structure, which can minimize the estimation error and error rate of the neural network. In a particular type of neural network, called a support vector machine (SVM), however, the focus is solely on reducing the operational risk associated with malfunction. The structure of an SVM network has many similarities to the MLP neural network, and the main difference lies in the way of learning. The general configuration of an SVM is depicted in Fig. 16. The self-organizing map (SOM) is a specific type of neural network that is quite similar to those studied in terms of functionality, structure, and application. The basic idea of self-organizing mapping is inspired by the functional division of the cerebral cortex, and its main application is to solve a problem known as "unmanaged learning." In

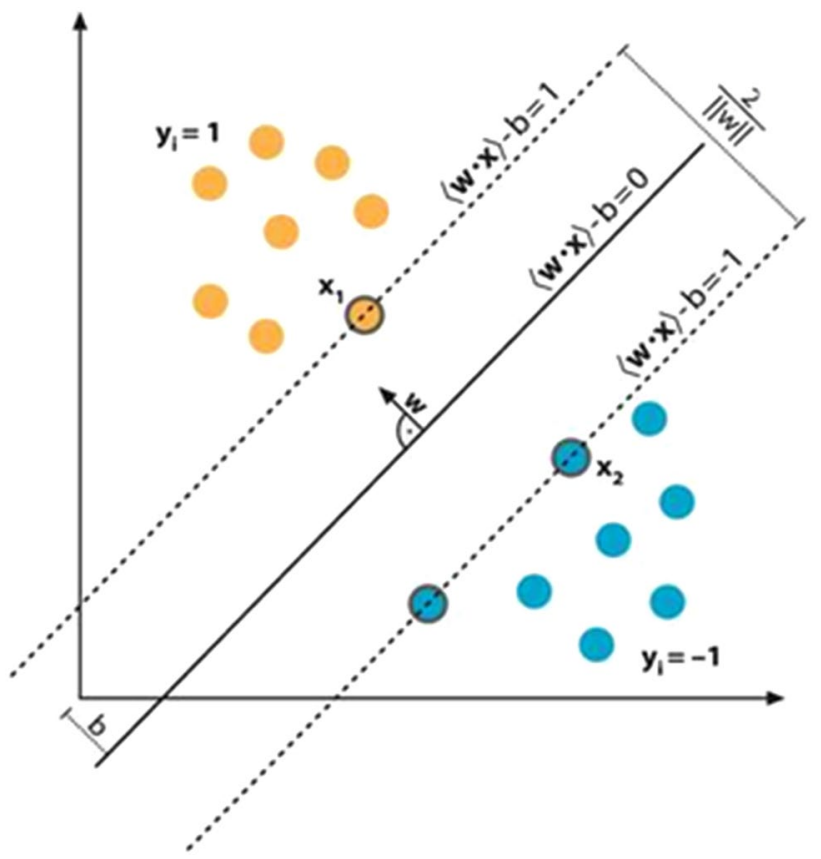

Fig. 15 The general configuration of an RBF

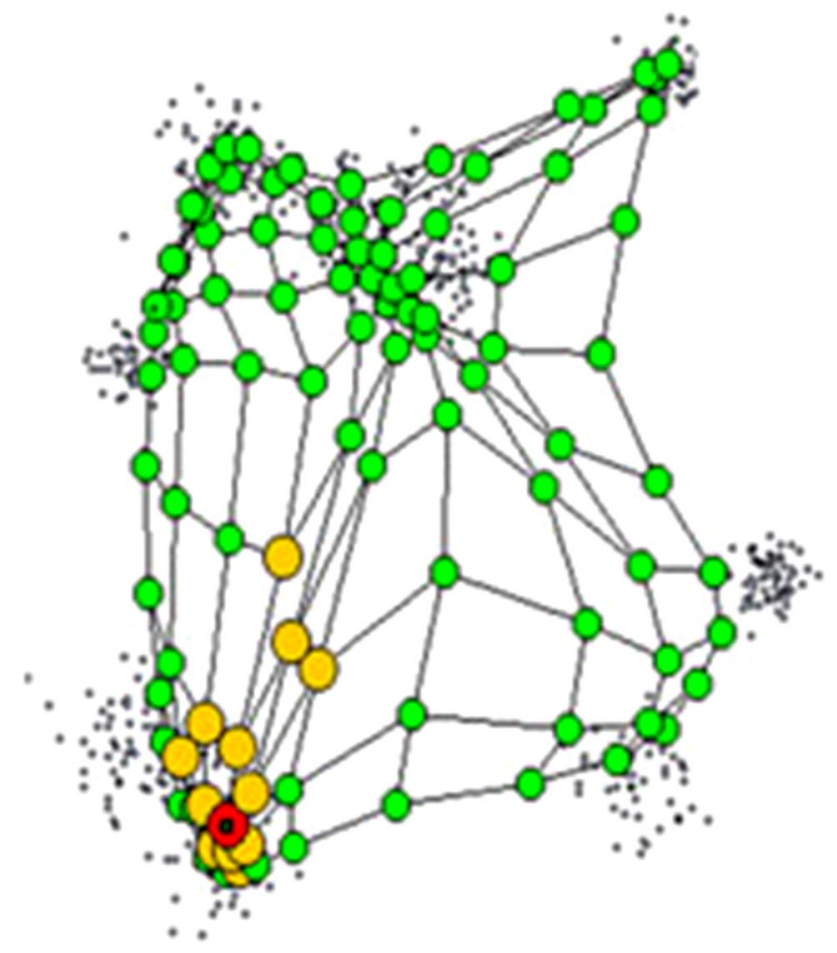

Fig. 16 The general configuration of a SVM

fact, the main function of a SOM is to find similarities and clusters among a vast array of data at its disposal. This is similar to what the human brain does and has classified 
(or better to say clustered) a bunch of sensory and motor inputs to the brain. The general configuration of a SOM is depicted in Fig. 17.

\subsection{ANN for the liquefaction prediction}

In this paper, an MLP ANN is configured to predict liquefaction. In this regard, four sets of different MLP ANNs with different characteristics are configured to establish a better prediction model for LPI. The specific characteristics of these models are presented in Table 5. An important difference between these ANN models is the number of neurons in the hidden layer, where a total set of 5-20 neurons is utilized for this purpose. The configuration of the ANN1 for predicting liquefaction is presented in Fig. 18.

\subsection{Results of the ANN analysis}

The numerical results of the ANN training process are presented in this section. The liquefaction prediction process is estimated through different ANN models to select an effective ANN model. Based on the presented information in the previous sections in terms of the experimental liquefaction results and the specific characteristics of the ANN

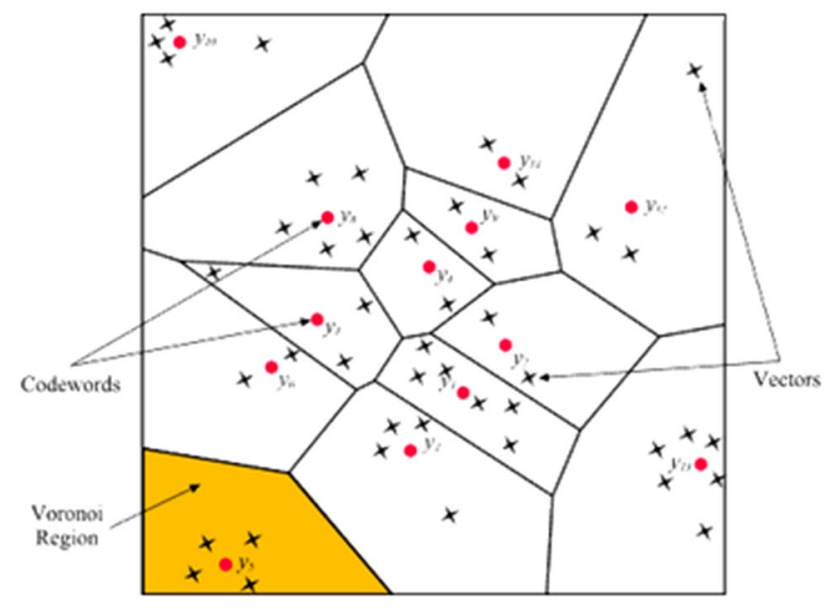

Fig. 17 The general configuration of a SOM (schematic view)

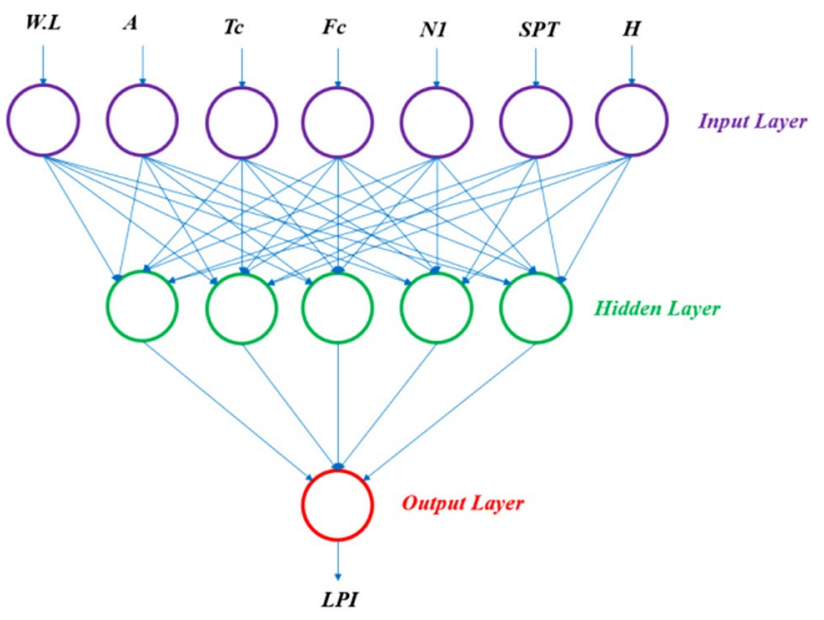

Fig. 18 The configuration of the ANN1 for liquefaction prediction

models, the training process of the ANNs is conducted based on the use of the Levenberg-Marquardt backpropagation MLP for training the ANNs. In this process, the training, validation, and test ratios are selected as $70 \%, 15 \%$, and $15 \%$ of the total data, respectively. The ANN training results are presented in Table 6 . Based on the provided details for the ANN models, the performance and convergence history of the training process for this network are presented in Figs. 19 and 20, respectively, while the error histogram of this network is depicted in Fig. 21.

Based on the provided details of the training process for the liquefaction in the ANN models, the training regressions are presented in Figs. 22, 23, 24 and 25. The regression for the training, validation, and test phases, as well as the overall regression of the network are presented in these figures. Based on the trained neural network for predicting liquefaction through ANN models, the overall performance of this network is examined via the provided input data to evaluate the exactness of the network. The performance evaluations of the ANN1 based on the predicted and experimental data are presented in Figs. 26, 27, 28 , and 29. Based on the results in Table 6 and illustrations, it is evident that ANN4 has a better performance in predicting LPI, which could be considered as the best ANN for
Table 5 The specific characteristics of different ANN models

\begin{tabular}{|c|c|c|c|c|c|c|}
\hline \multirow[t]{2}{*}{ ANN Num } & \multicolumn{3}{|c|}{ Number } & \multicolumn{2}{|c|}{ Transfer functions (TF) } & \multirow{2}{*}{$\begin{array}{l}\text { Data } \\
\text { Num. of } \\
\text { exp. Data }\end{array}$} \\
\hline & Inputs & Outputs & $\begin{array}{l}\text { Neurons in hid- } \\
\text { den layers }\end{array}$ & Hidden layer & Output layer & \\
\hline ANN1 & 7 & 1 & 5 & Tan-Sigmoid & Tan-Sigmoid & 100 \\
\hline ANN2 & 7 & 1 & 10 & Tan-Sigmoid & Tan-Sigmoid & 100 \\
\hline ANN3 & 7 & 1 & 15 & Tan-Sigmoid & Tan-Sigmoid & 100 \\
\hline ANN4 & 7 & 1 & 20 & Tan-Sigmoid & Tan-Sigmoid & 100 \\
\hline
\end{tabular}

Tan-Sigmoid: Hyperbolic tangent sigmoid transfer function 
Table 6 The specific characteristics of ANN models

\begin{tabular}{lllll}
\hline & ANN1 & ANN2 & ANN3 & ANN4 \\
\hline Progress & & & & \\
Epoch & 18 & 9 & 9 & 10 \\
Perf & 0.0033 & 0.00295 & 0.000765 & $4.55 \mathrm{E}-05$ \\
Gradient & 0.00891 & 0.00163 & 0.00834 & 0.00154 \\
Mu & $1.00 \mathrm{E}-06$ & 0.0001 & $1.00 \mathrm{E}-05$ & $1.00 \mathrm{E}-05$ \\
Performance & & & & \\
Train & 0.0042 & 0.0107 & 0.0155 & 0.0019 \\
Validation & 0.0052 & 0.0116 & 0.0027 & 0.0067 \\
Test & 0.0086 & 0.0037 & 0.0175 & 0.0043 \\
Regression & & & & \\
Train & 0.95677 & 0.90948 & 0.91523 & 0.98191 \\
Validation & 0.87532 & 0.922 & 0.96066 & 0.94994 \\
Test & 0.97985 & 0.9133 & 0.91165 & 0.94223 \\
All & 0.95098 & 0.90474 & 0.89356 & 0.97073 \\
\hline
\end{tabular}

practical applications. To evaluate the overall performance of the ANN4 through different training processes, one of the input data is selected to verify the ANN4, for which the $\mathrm{BH}-3$ is utilized with an LPI value of 17. The training process for ANN4 is repeated 10 times, and the LPI in each of them is predicted through the trained networks. As Fig. 30 clearly shows, the ANN4 is capable of predicting LPI values via maximum errors of lower than $10 \%$ in most cases.

In the regressions, the inputs are the $\mathrm{H}$ as the maximum depth of the soil levels, SPT as the SPT value, $\left(N_{1}\right)_{60 c s}$ as the modified penetration number equivalent to clean sand, FC as the fines content percentage in soil, TC as the depth of the soil layer, $A$ as the ground acceleration of the soil, and W.L as the maximum water level in meter while the output is the liquefaction of the soil.

In the next step, an additional verification procedure is conducted for the best ANN model of the previous section to demonstrate the overall capability of the trained ANN model in dealing with some unknown borehole data from Tabriz city. It should be noted that these data have not been utilized for the training process of the ANN models in the previous section. The characteristics of these soil data are presented in Table 7. The process is verified using the configuration of the ANN4, which has a better regression $(R)$ value of 0.97073 . The results of the ANN4 for each of the additional boreholes (Table 7) are provided in Table 8 accordingly. It should be noted that the ANN4 is capable of predicting the LPI with an acceptable error rate of less than 5 in all of the cases.

\section{Conclusions}

Many empirical approaches have been proposed to predict the liquefaction potential, each of which has its own advantages and disadvantages. Soil liquefaction is a phenomenon in which saturated soil completely loses its strength and hardness and behaves like a liquid due to the severe stress it entails. This stress can be caused by earthquakes or sudden changes in soil stress conditions. In this paper, a novel prediction approach based on an ANN is proposed to adequately predict the liquefaction potential of a specific range of soil properties. To this end, a whole set of 100 soil data is collected to calculate the liquefaction potential using empirical approaches in Tabriz city, Iran. Then, the results of the empirical approaches are utilized for data training in an ANN, which is considered as an option for predicting liquefaction. The achieved configuration of the neural network is utilized to predict the liquefaction of 10 other data sets for validation purposes. The obtained results proved that the well-trained ANN is capable of predicting the liquefaction potential by an error value of less than $5 \%$, which represents the reliability of the proposed approach. It should be noted that the present study is the first attempt to comprehensively predict liquefaction in the Tabriz metropolis. Hence, the results of this paper could be utilized for future applications in different fields.

In this research, the finite-fault method by EXSIM 14 program and its reflection from the bedrock to the ground surface by Deepsoil v6.1 software were used by performing seismic calculations to determine the maximum vibrational acceleration (PGA). By processing the data in the GIS environment, a liquefaction zoning map was also conceived for this city. Moreover, a process was presented for predicting liquefaction capability using data training in the ANN and its control. Therefore, since comprehensive studies have not been conducted on the possibility of liquefaction in this area, the innovation of this research is evident. It should also be noted that the results of this research can be utilized as a prediction method before the excavations, which reduces the overall costs of the earth investigations. 


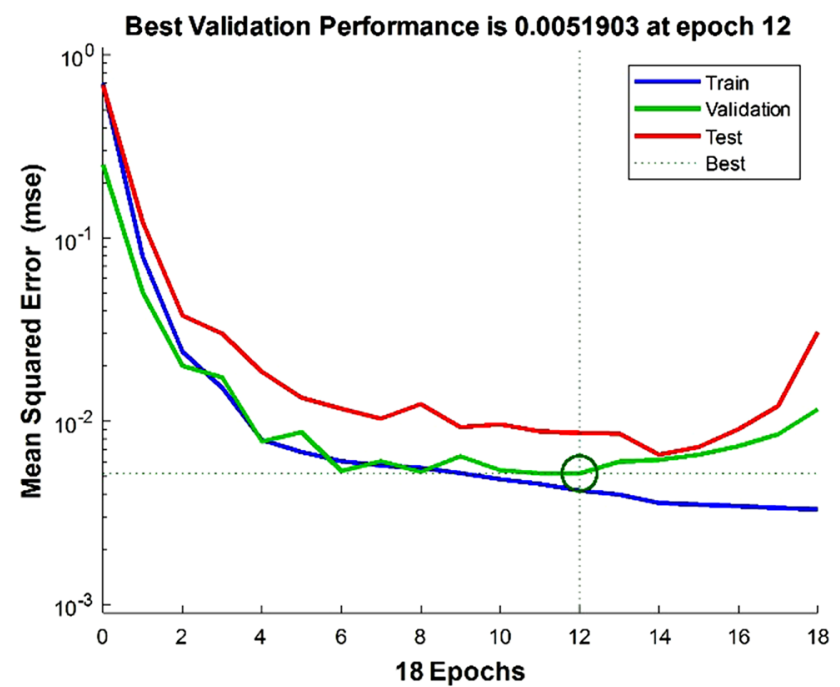

(a) ANN 1

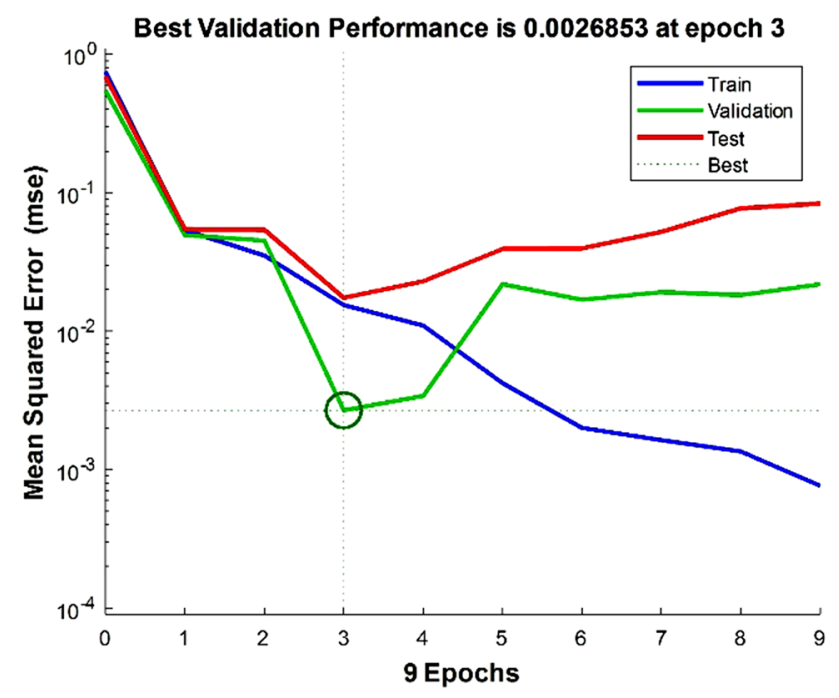

(c) ANN 3

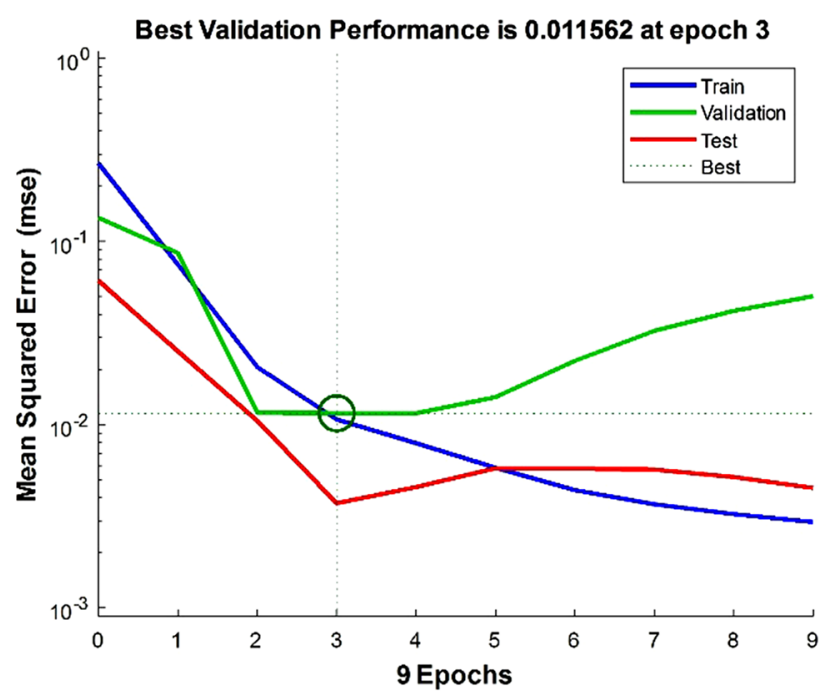

(b) ANN 2

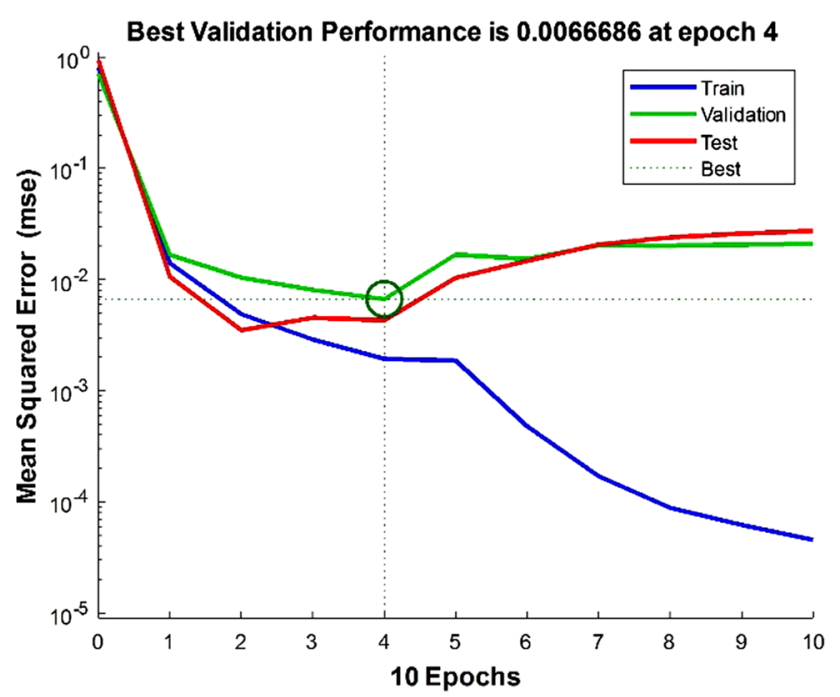

(d) ANN 4

Fig. 19 The performance of the ANN models for liquefaction prediction, a Model No.1 (ANN 1), b Model No.2 (ANN 2), c Model No.3 (ANN 3), d Model No.4 (ANN 4) 

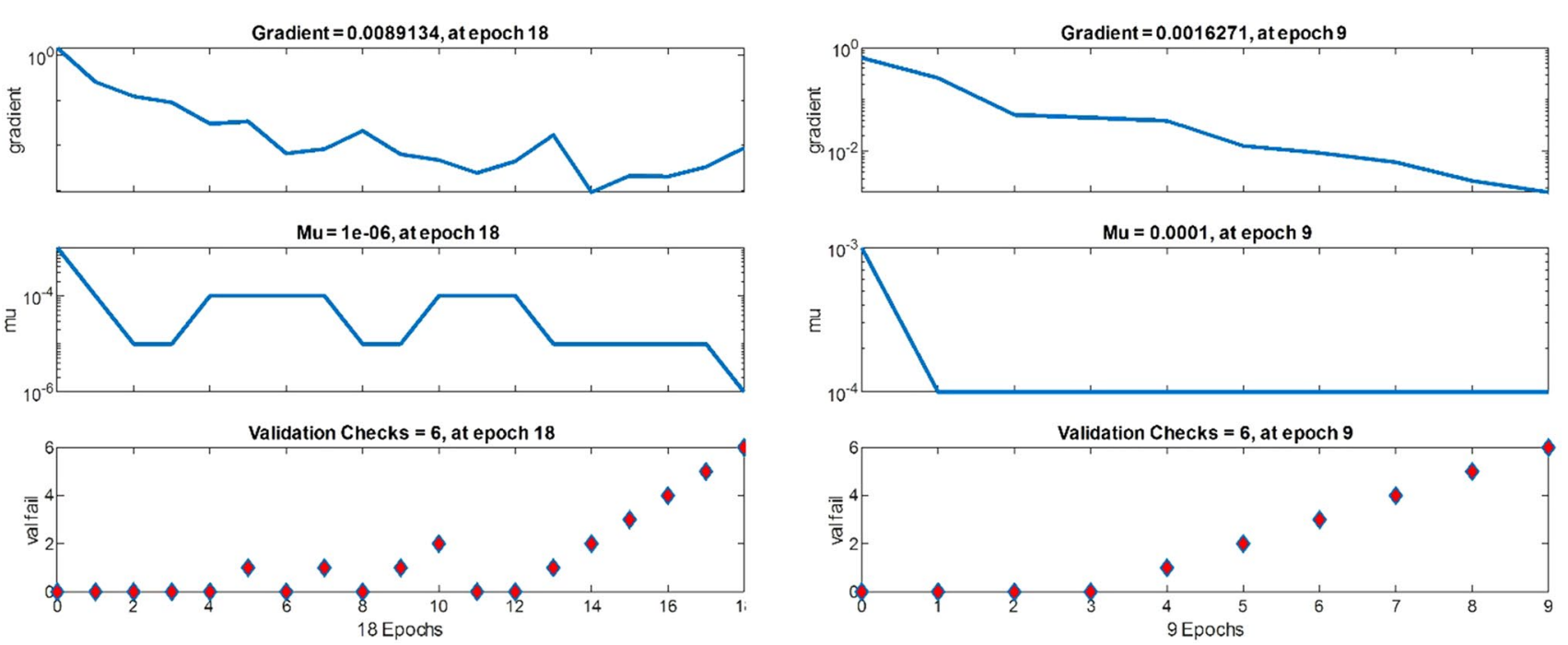

(a) ANN 1

(b) ANN 2
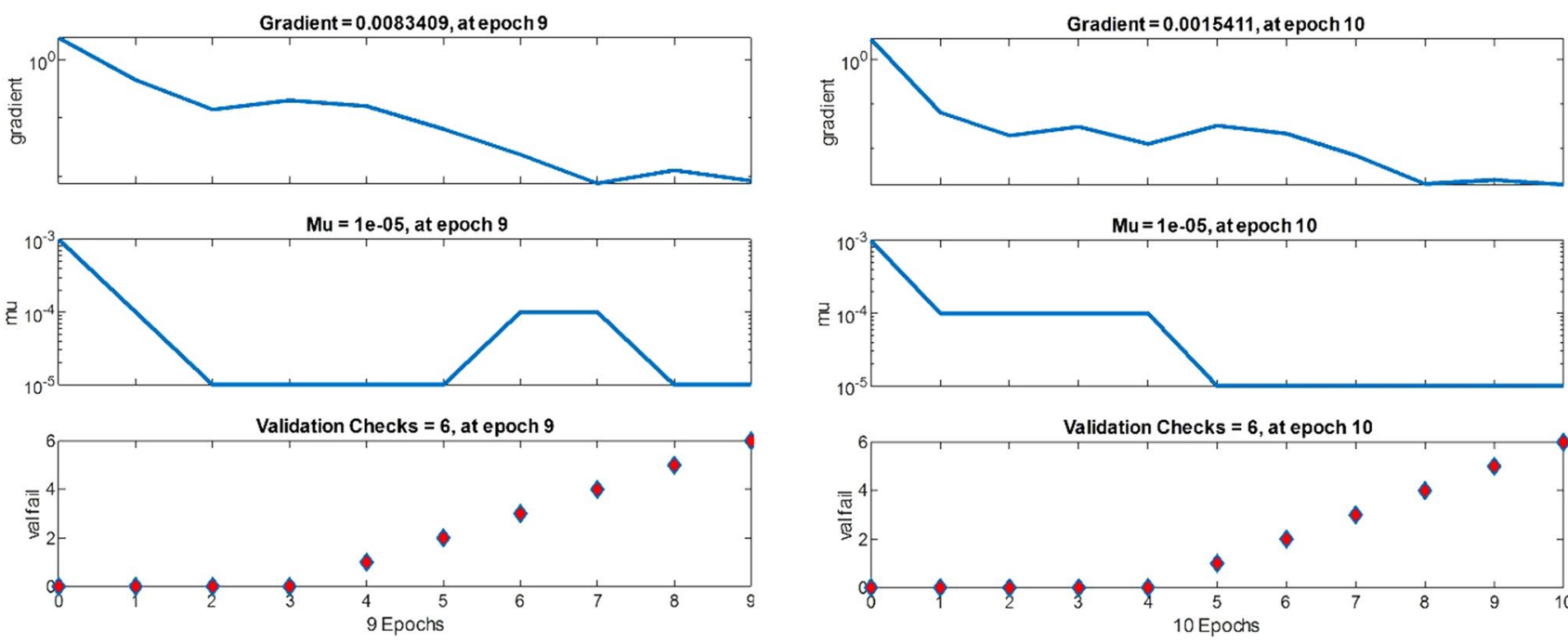

(c) ANN 3

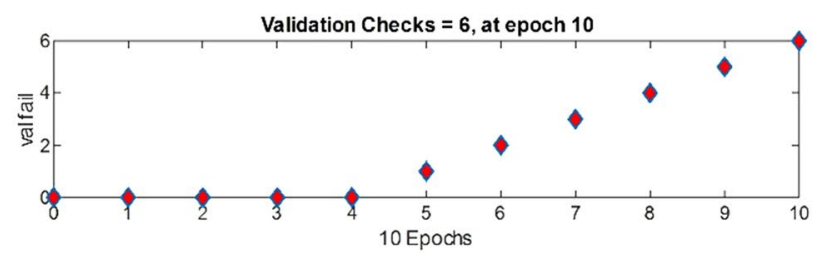

(d) ANN 4

Fig. 20 The convergence history of the ANN models for liquefaction prediction, a Model No.1 (ANN 1), b Model No.2 (ANN 2), c Model No.3 (ANN 3), d Model No.4 (ANN 4) 


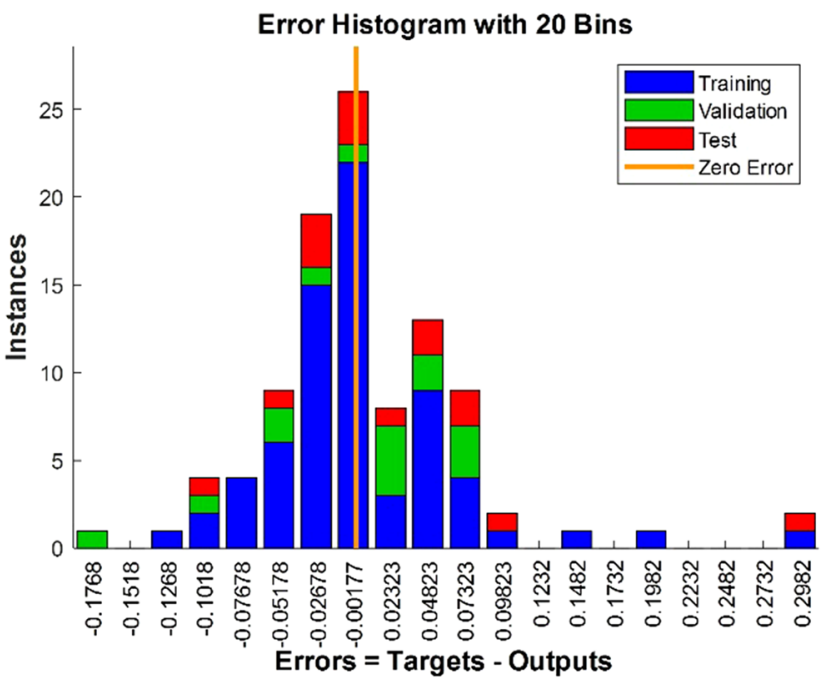

(a) ANN 1

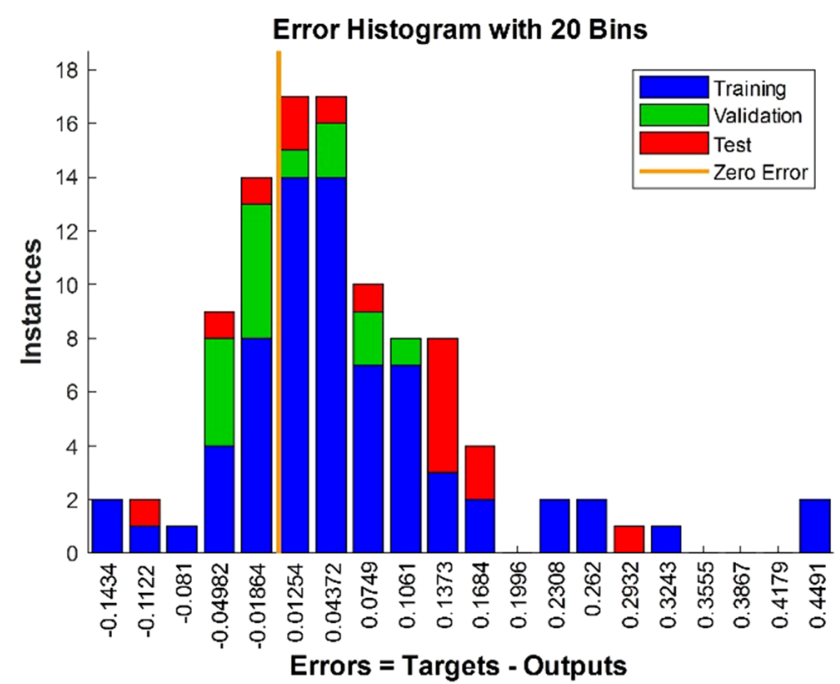

(c) ANN 3

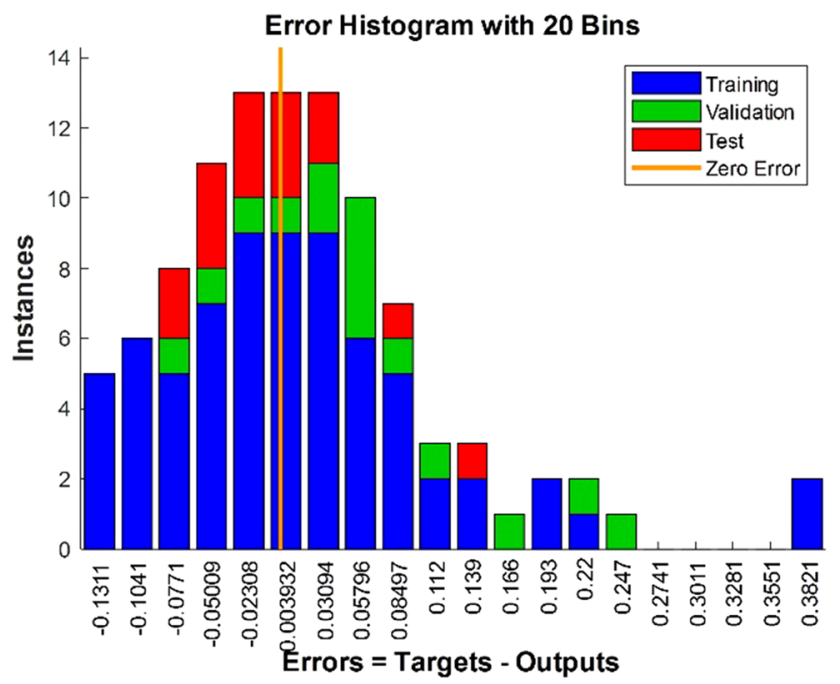

(b) ANN 2

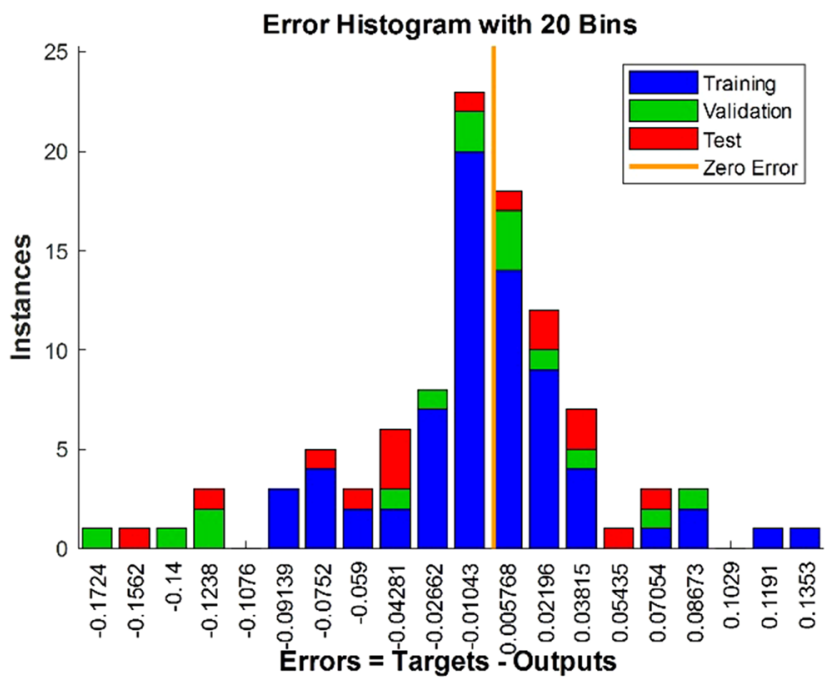

(d) ANN 4

Fig. 21 The error histogram history of the ANN models for liquefaction prediction, a Model No.1 (ANN 1), b Model No.2 (ANN 2), c Model No.3 (ANN 3), d Model No.4 (ANN 4) 

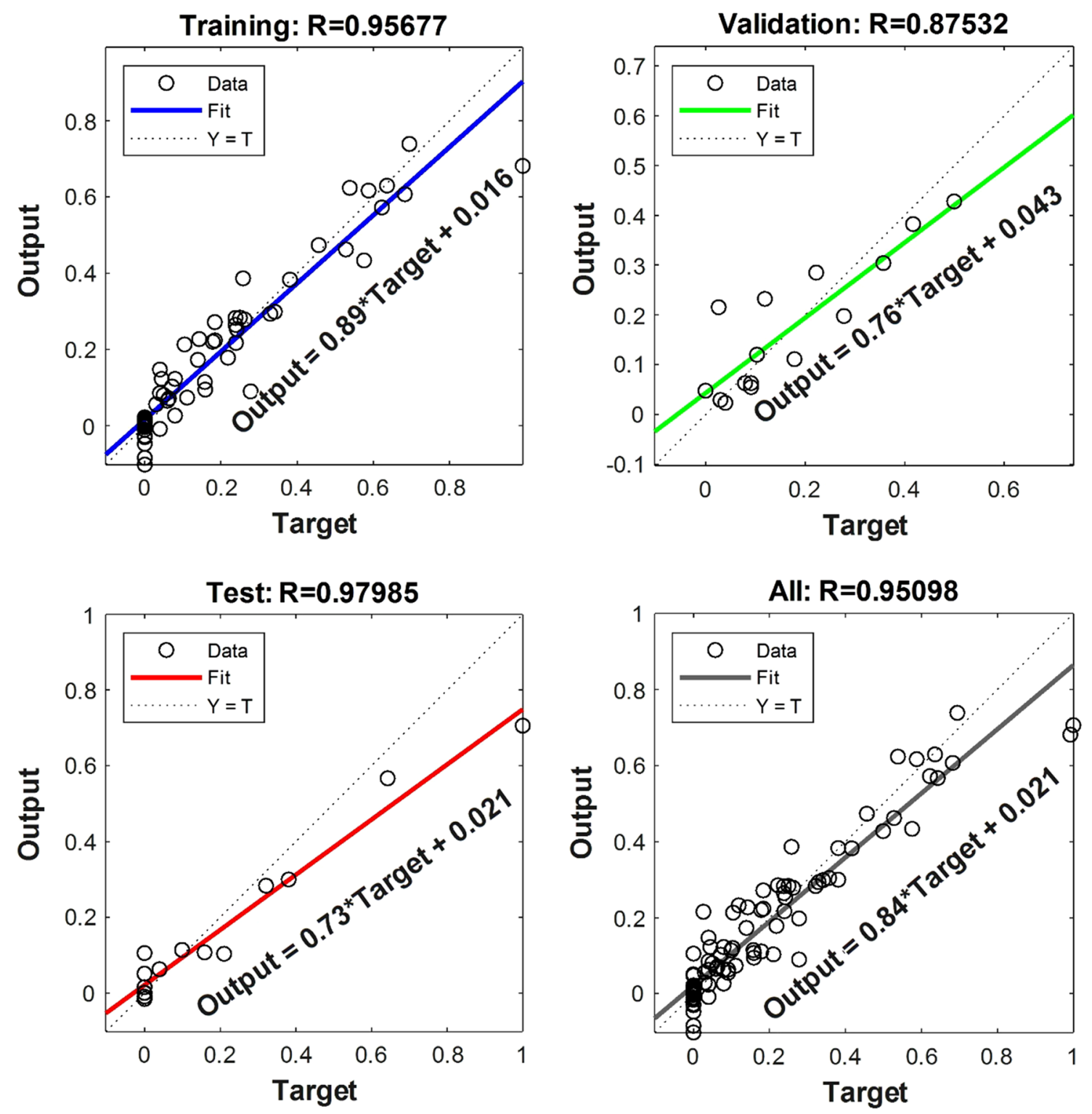

Fig. 22 The training regression of the Model No.1 (ANN 1) for liquefaction prediction 

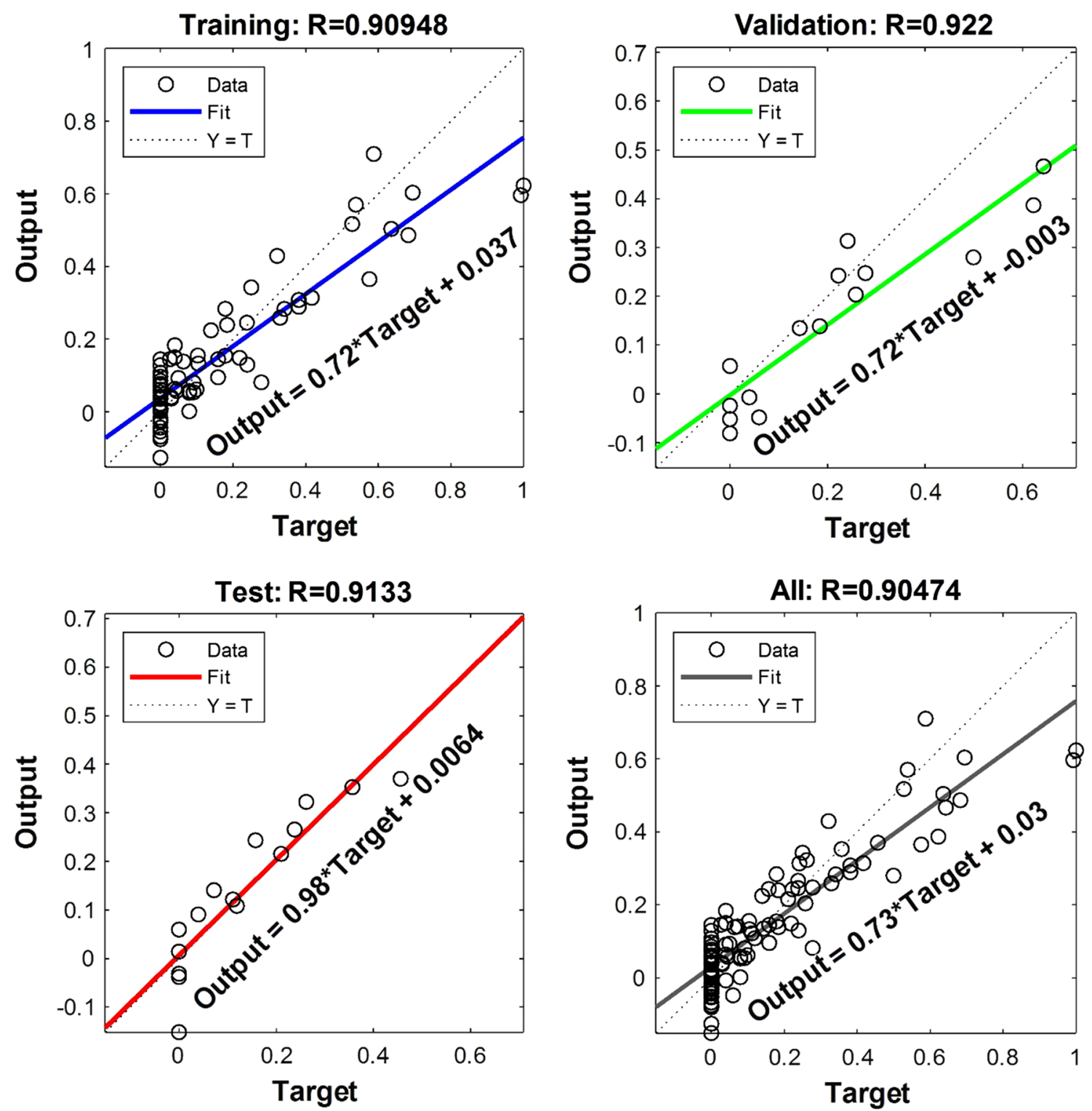

Fig. 23 The training regression of the Model No.2 (ANN 2) for liquefaction prediction 

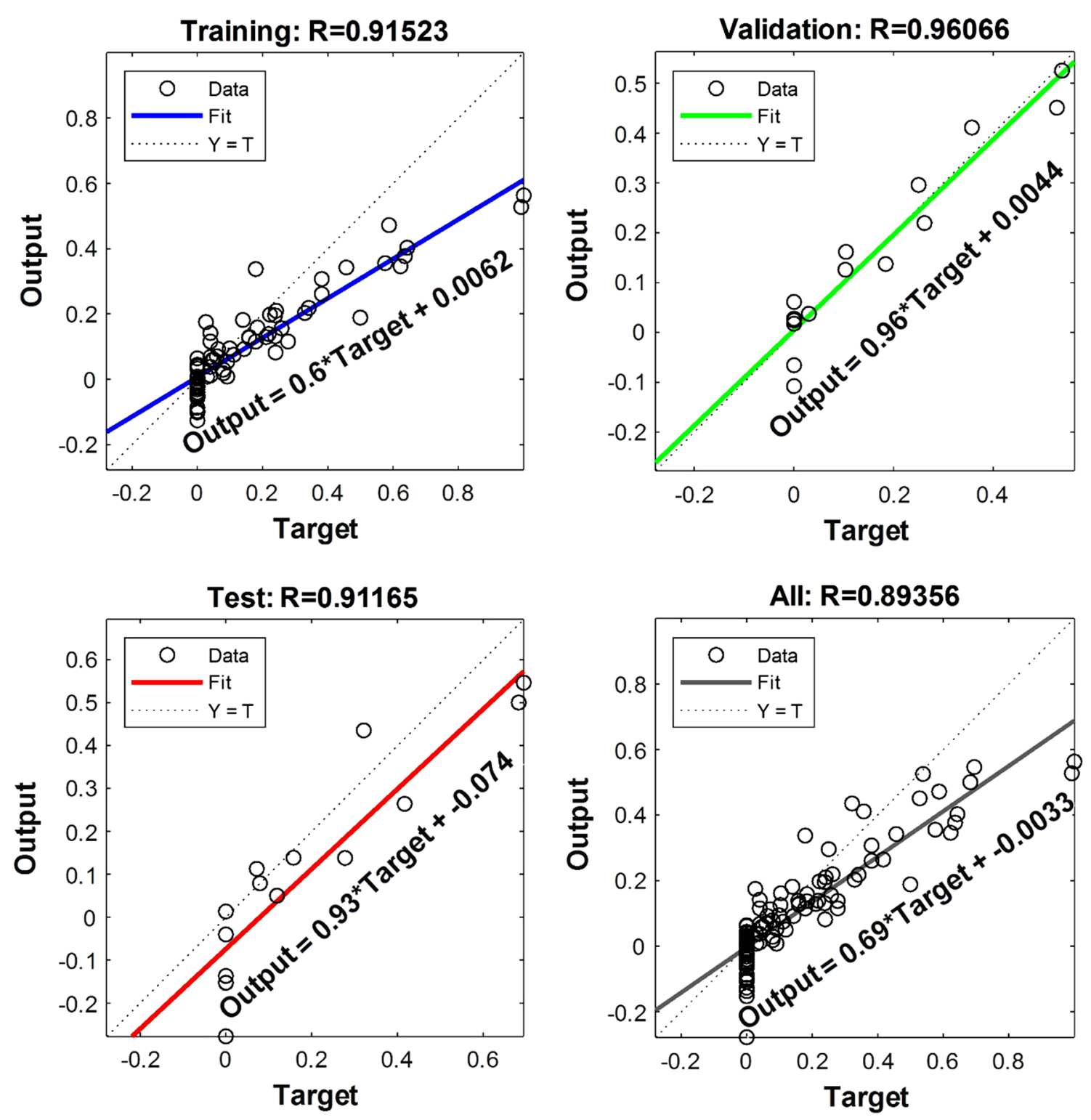

Fig. 24 The training regression of Model No.3 (ANN 3) for liquefaction prediction 

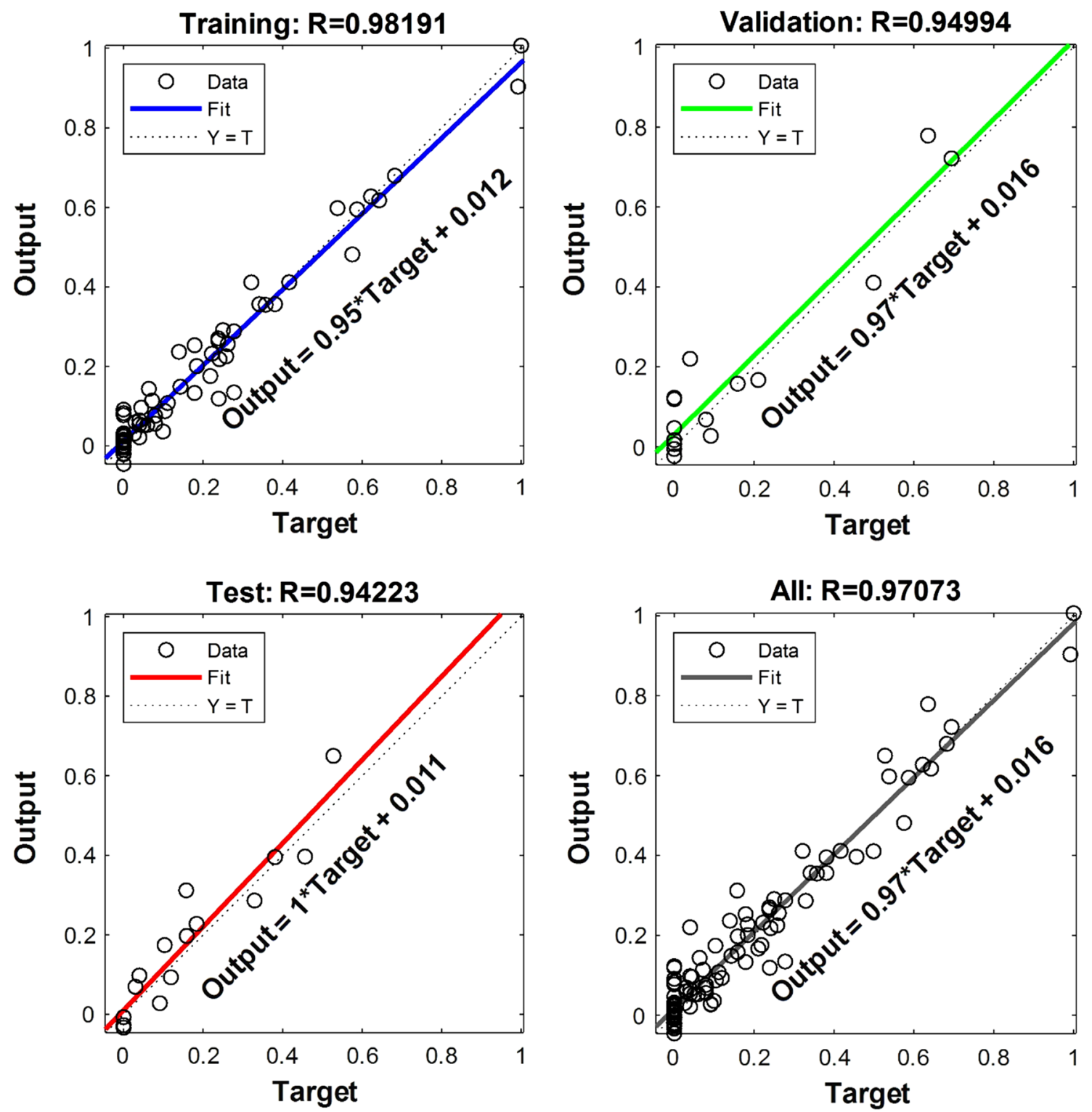

Fig. 25 The training regression of Model No.4 (ANN 4) for liquefaction prediction 


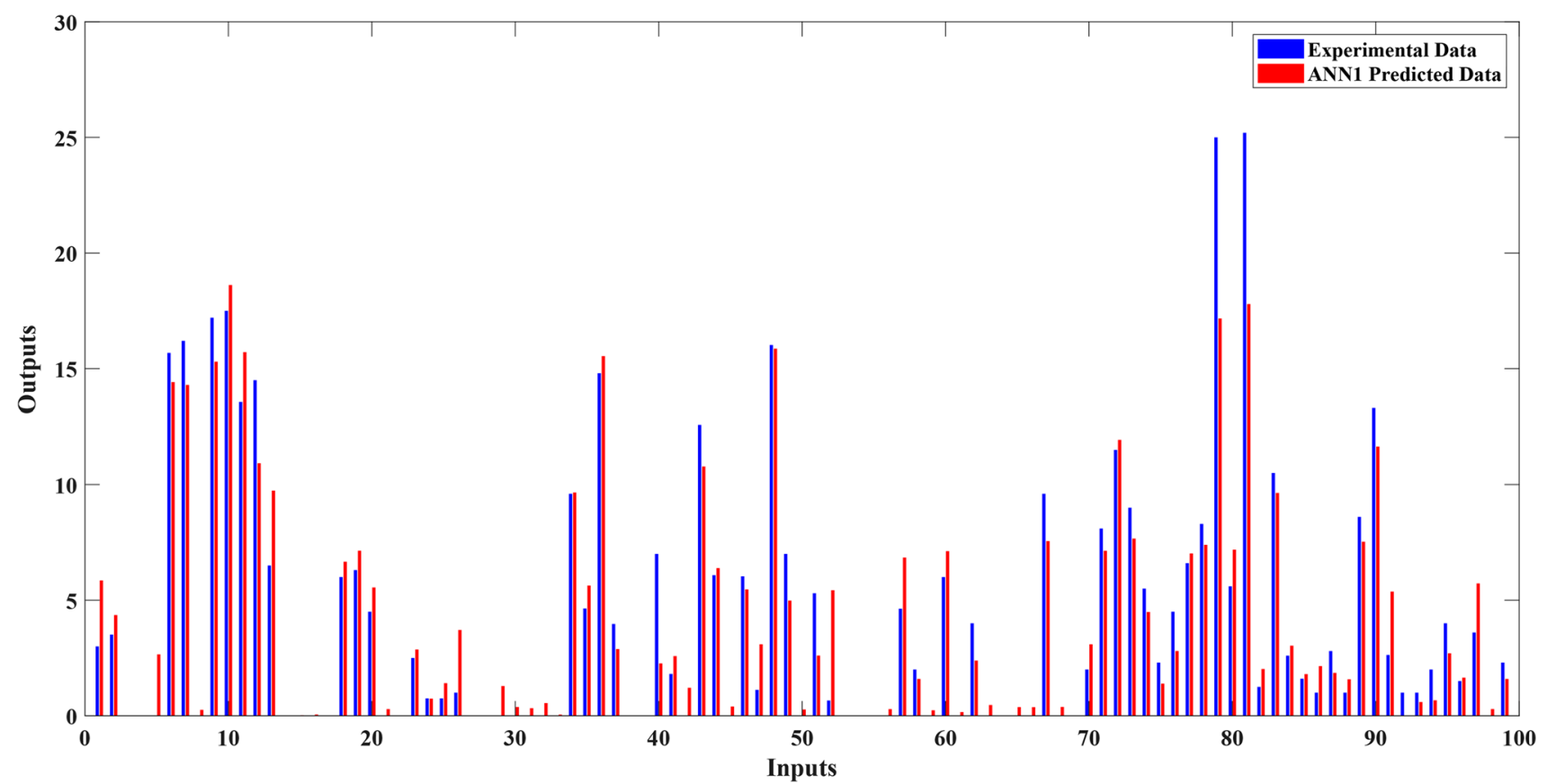

Fig. 26 The performance evaluation of the Model No.1 (ANN 1) based on the predicted and experimental data

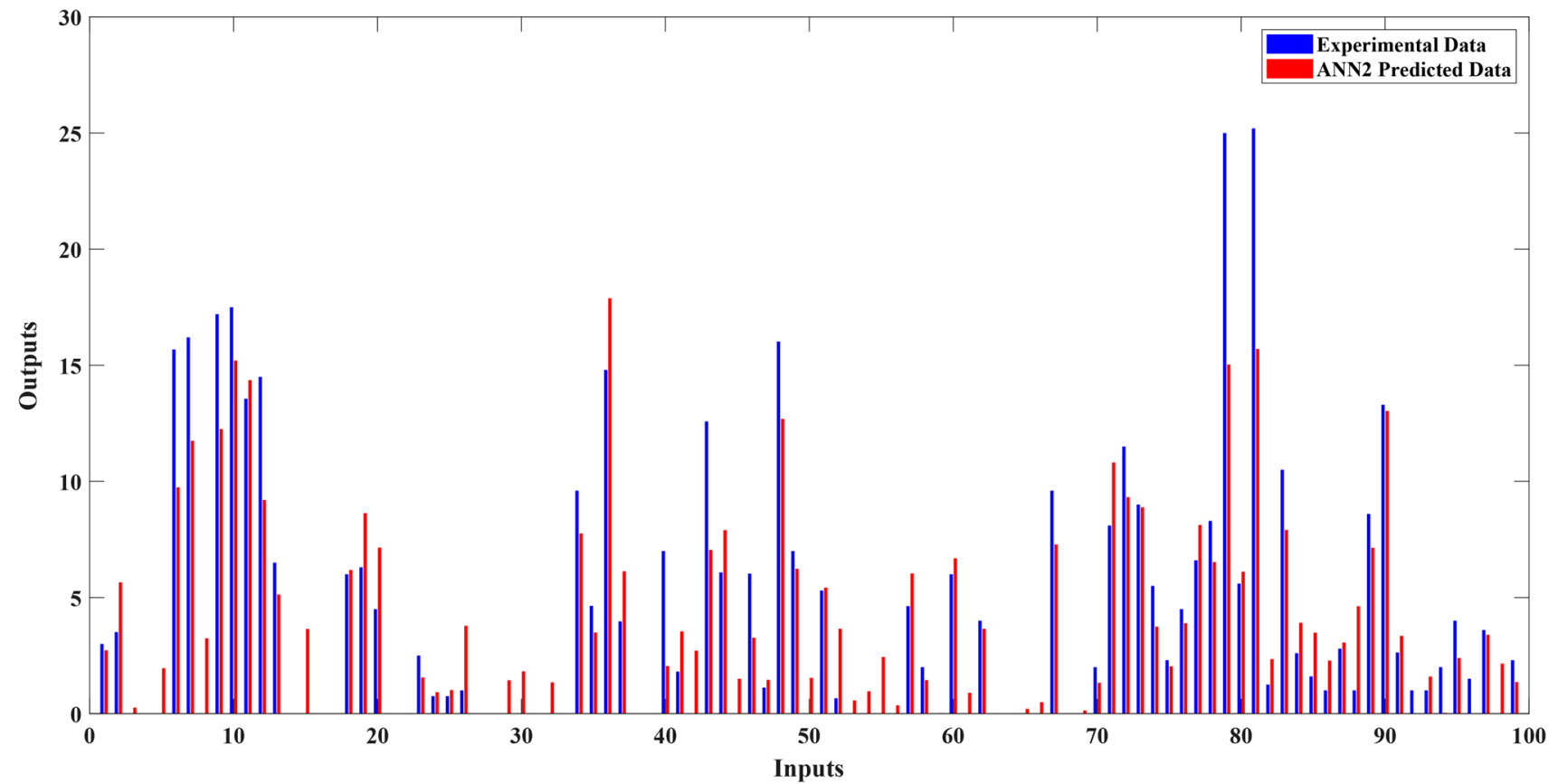

Fig. 27 The performance evaluation of Model No.2 (ANN 2) based on the predicted and experimental data 


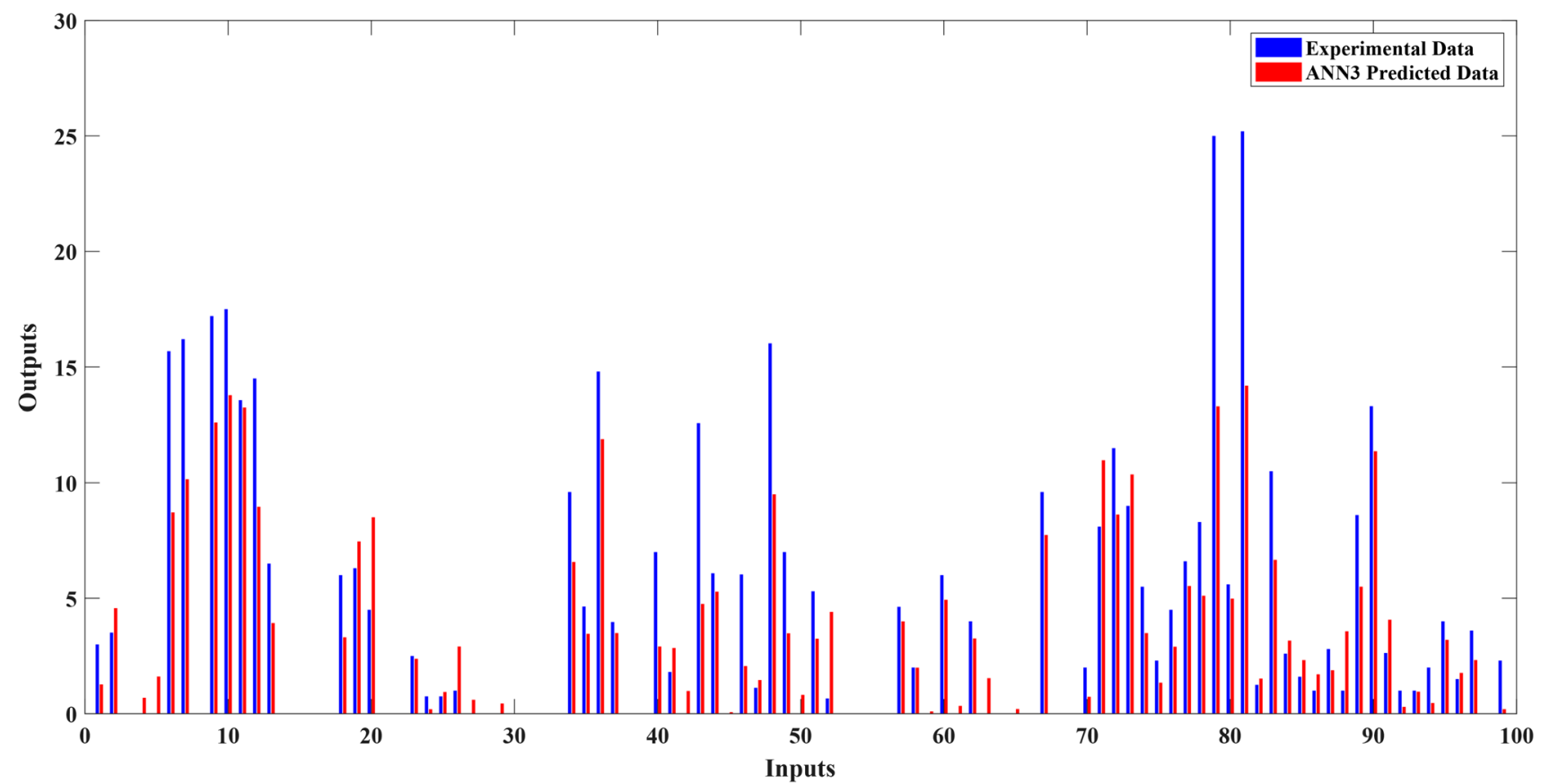

Fig. 28 The performance evaluation of Model No.3 (ANN 3) based on the predicted and experimental data

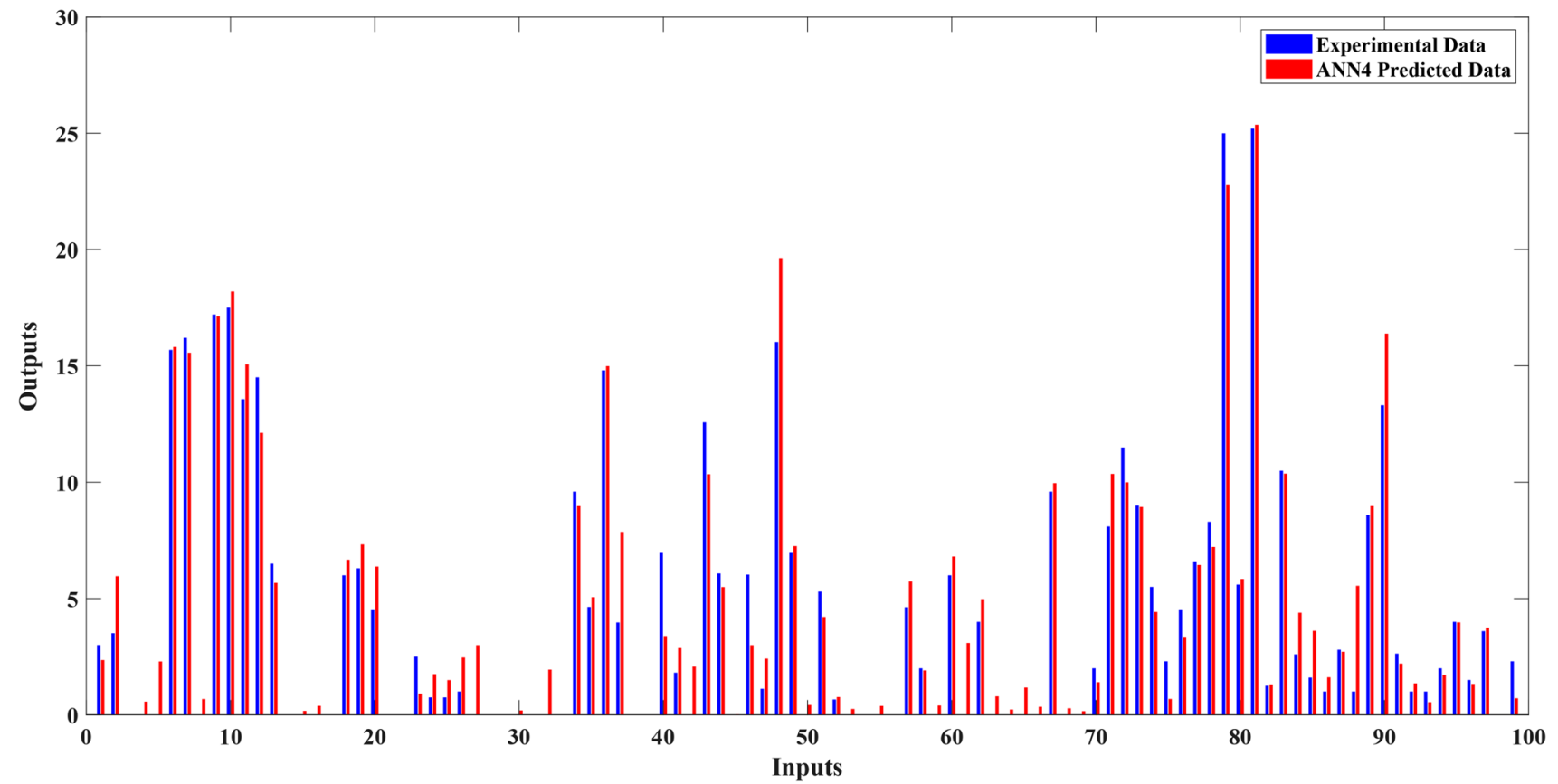

Fig. 29 The performance evaluation of Model No.4 (ANN 3) based on the predicted and experimental data 


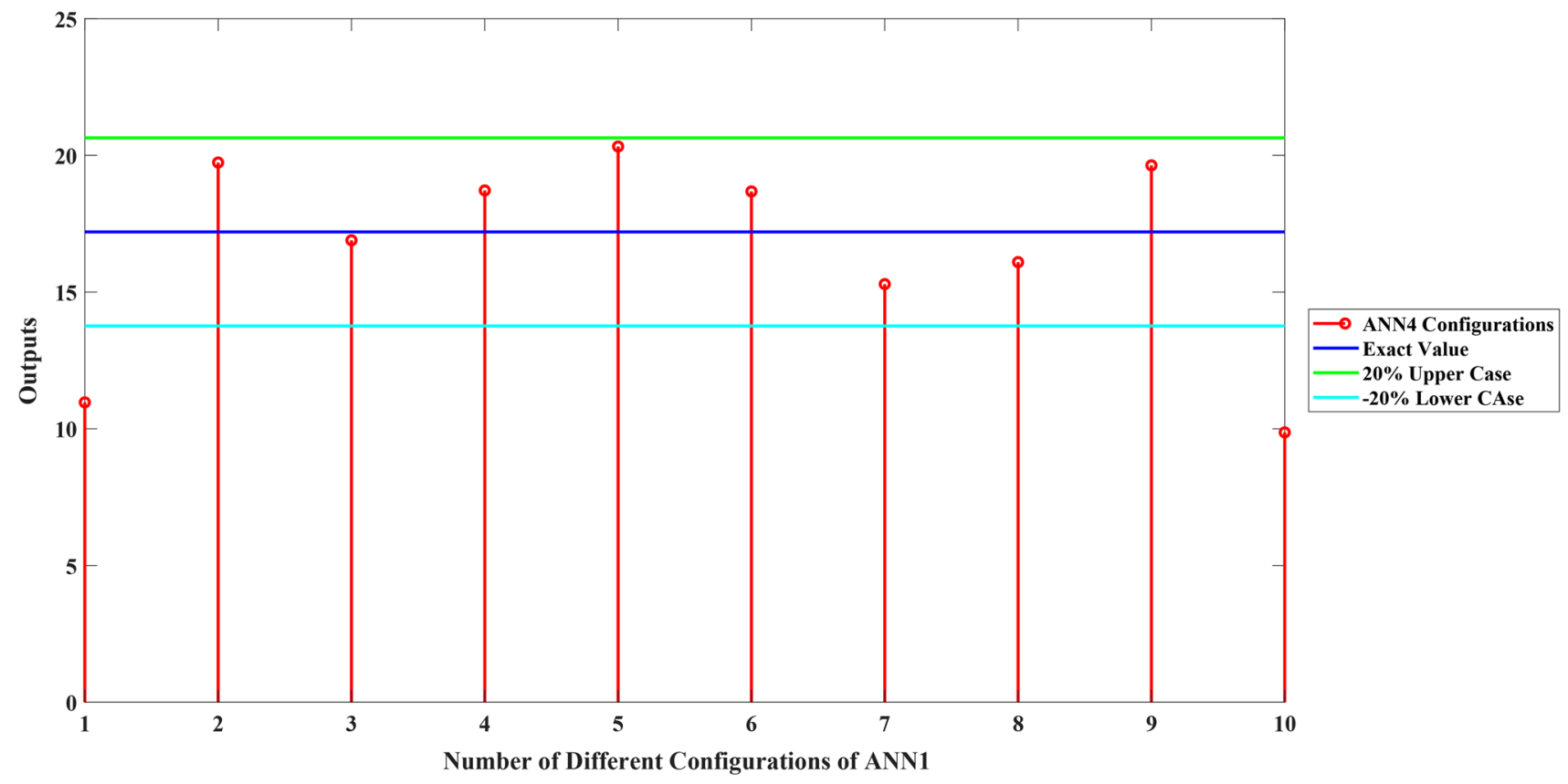

Fig. 30 The performance evaluation of the Model No. 4 (ANN 4) with different configurations

Table 7 Characteristics of the additional boreholes

\begin{tabular}{lllllllllr}
\hline No. & ID & $H(\mathrm{~m})$ & SPT* $^{*}$ & $\left(N_{1}\right)_{60 C S}$ & FC $(\%)$ & TC $(\mathrm{m})$ & $A(\mathrm{~g})$ & W.L $(\mathrm{m})$ & LPI \\
\hline 1 & BHV-1 & 10 & 28 & 22.8398 & 18 & 10 & 0.7 & 7 & 8.71 \\
2 & BHV-2 & 12 & 26 & 22.8108 & 36 & 3 & 0.78 & 8 & 10.72 \\
3 & BHV-3 & 11 & 24 & 23.0957 & 31 & 4 & 0.66 & 8 & 12.15 \\
4 & BHV-4 & 15 & 16 & 14.8661 & 39 & 4 & 0.8 & 11 & 9.26 \\
5 & BHV-5 & 13 & 24 & 21.3532 & 40 & 5 & 0.65 & 10 & 9.01 \\
\hline
\end{tabular}

*The provided SPT is for the soil layer with a higher possibility of liquefaction (with larger SPT values), and the other parameters are related to the selected SPT

Table 8 Results of the ANN4 for the additional boreholes

\begin{tabular}{llrcc}
\hline No. & ID & \multicolumn{1}{c}{ LPI } & Predicted LPI & Error \\
\hline 1 & BHV-1 & 8.71 & 8.57 & $1.6 \%$ \\
2 & BHV-2 & 10.72 & 11.15 & $3.8 \%$ \\
3 & BHV-3 & 12.15 & 12.19 & $0.3 \%$ \\
4 & BHV-4 & 9.26 & 8.83 & $4.6 \%$ \\
5 & BHV-5 & 9.01 & 9.08 & $0.7 \%$ \\
\hline
\end{tabular}

\section{Declarations}

Conflict of interest The authors declare that they have no conflict of interest.

Open Access This article is licensed under a Creative Commons Attribution 4.0 International License, which permits use, sharing, adaptation, distribution and reproduction in any medium or format, as long as you give appropriate credit to the original author(s) and the source, provide a link to the Creative Commons licence, and indicate if changes were made. The images or other third party material in this article are included in the article's Creative Commons licence, unless indicated otherwise in a credit line to the material. If material is not included in the article's Creative Commons licence and your intended use is not permitted by statutory regulation or exceeds the permitted use, you will need to obtain permission directly from the copyright holder. To view a copy of this licence, visit http://creativecommons. org/licenses/by/4.0/.

\section{References}

1. Andrus RD, Piratheepan P, Ellis BS, Zhang J, Juang HC (2004) Comparing liquefaction evaluation methods using penetration Vs relationship. J Soil Dyn Earthq Eng 24:713-721

2. Andrus RD, Stokoe KH, Juang CH (2004) Guide for shearwave-based liquefaction potential evaluation. Earthq Spectra 20:258-308

3. Asvar F, Shirmohammadi Faradonbeh A, Barkhordari K (2018) Predicting potential of controlled blasting-induced liquefaction using neural networks and neuro-fuzzy system. Scientia Iranica 25(2):617-631 
4. Atkinson GM, Silva W (1997) An empirical study of earthquake source spectra for California earthquakes. Bull Seismolology Soc Am 87:97-113

5. Atkinson G, Goda K, Assatourians K (2011) Comparison of nonlinear structural responses for accelerograms simulated from the stochastic finite-fault approach versus the hybrid broadband approach. Bull Seismol Soc America 101:2967-2980

6. Atkinson G, Assatourians K (2014) Implementation and validation of EXSIM (a stochastic finite-fault ground-motion simulation algorithm) on the SCEC broadband platform. Seismol Res Lett 86:N1

7. Bagheri M, Dabiri R (2019) Liquefaction potential hazard in South east of Khoy. Adv Res Civil Eng 1(4):9-18

8. Beresnev I, Atkinson G (1998) FINSIM: a FORTRAN program for simulating stochastic acceleration time histories from finite faults. Seismol Res Lett 69:270-274

9. Boore DM (1983) Stochastic simulation of high-frequency ground motions based on seismological models of the radiated spectra. Bull Seismol Soc Am 73:1865-1894

10. Boore DM (2003) Prediction of ground motion using the stochastic method. Pure Appl Geophys 160:635-676

11. Boore DM (2005) SMSIM-Fortran programs for simulating ground motions from earthquakes: version 2.3, A revision of OFR 96-80-A, A modified version of OFR 00-509. 59. [Online] Available from: (http://daveboore.com/software_online.html)

12. Boore DM (2009) Comparing stochastic point-and finite-source ground-motion simulations: SMSIM and EXSIM. Bull Seismol Soc Am 99:3202-3216

13. Brune JN (1970) Tectonic stress and the spectra of seismic shear waves from earthquakes. J Geophys Res 75:4997-5009

14. Cetin KO, Seed RB, Der Kiureghian A, Tokimatsu K, Harder LF $J r$, Kayen RE, Moss RE (2004) Standard penetration test-based probabilistic and deterministic assessment of seismic soil liquefaction potential. J Geotech Geoenviron Eng 130(12):1314-1340

15. Dabiri R, Askari F, Shafiee A, Jafari MK (2011) Shear wave velocity based Liquefaction resistance of sand-silt mixtures: deterministic versus probabilistic approach. Iran J Sci Technol Trans Civil Eng 35(C2):199-215

16. Das SK, Mohanty R, Mohanty M, Mahamaya M (2020) Multiobjective feature selection (MOFS) algorithms for prediction of liquefaction susceptibility of soil based on in situ test methods. Nat Hazards 103:2371-2393

17. Drennov AF, Dzhurik VI, Serebrennikov SP, Bryzhak EV, Drennova NN (2013) Acceleration response spectra for the earthquakes of the southwestern flank of the Baikal Rift Zone. Russ Geol Geophys 54(2):223-230

18. Eker AM, Akgun H, Kockar MK (2012) Local site characterization and seismic zonation study by utilizing active and passive surface wave methods: a case study for the northern side of Ankara, Turkey. Eng Geol 151:64-81

19. Ghasemian M, Dabiri R, Mahari R (2018) Settlements hazard of soil due to liquefaction along Tabriz metro Line 2. Pamukkale Univ J Eng Sci 24(6):942-951

20. Ghobadi MH, Firuzi M, Asghari E (2016) Relationships between geological formations and ground water chemistry and their effects on concrete lining of tunnels (case study: Tabriz metro line 2). Environ Earth Sci 75:2-14

21. Hashash YMA, Grohalski DR, Philips CA (2010) Recent advances in non-linear site response analysis. In: 5th International Conference on Recent Advances in Geotechnical Earthquake Engineering and Soil Dynamics, San Diego, California

22. Hashash YMA, Musgrove MI, Harmon JA, Groholski DR, Phillips, CA, Park, D.(2016) DEEPSOIL 6.1, User Manual.

23. Hwang JH, Khoshnevisan S, Juang CH, Lu CC (2021) Soil liquefaction potential evaluation-An update of the HBF method focusing on research and practice in Taiwan. Eng Geol 280:105926
24. Idriss IM, Boulanger RW (2010) SPT-based liquefaction triggering procedures. Report no. UCD/CGM-10/02, Center for Geotechnical Modeling. University of California, Davis

25. Irikura K (1983) Semi-empirical estimation of strong ground motions during large earthquakes. Bull Disaster Preview Res Inst 33:63-104

26. Irikura K (1992) The construction of large earthquake by a superposition of small events. In: Proceedings of the Tenth World Conference on Earthquake Engineering, 10: 727-730

27. Irikura K, Kamae K (1994) Estimation of strong ground motion in broad-frequency band based on a seismic source scaling model and an empirical Green's function technique. Annual Geophys 37:1721-1743

28. Iwasaki, T., Tatsuoka, F., Tokida, K. and Yasuda, S. (1978). A Practical Method for Assessing SoilLiquefaction Potential Based on Case Studies at Various site in Japan. 5th Japan Earthquake EngineeringSymposium.Vol II: 641-648.

29. Iwasaki T, Tokida K, Tatsuoka F, Watanabe S, Yasuda S, Sato H (1982) Microzonation for soil liquefaction potential using simplified methods. In: Proceedings of 2nd International Conference on Microzonation, Seattle, p 1319-1330

30. Kaghazchi M, Dabiri R (2017) Comparison of liquefaction potential evaluation based on SPT and energy methods in Tabriz metro line 2. J Tethys 5(3):313-326

31. Kurnaz TF, Kaya Y (2019) A novel ensemble model based on GMDH-type neural network for the prediction of CPT-based soil liquefaction. Environ Earth Sci 78(11):3-14

32. Mele L, Flora A (2019) On the prediction of liquefaction resistance of unsaturated sands. Soil Dyn Earthq Eng 125:105689

33. Mohammadi DS, Firuzi M, Kaljahi EA (2015) Geologicalgeotechnical risk in the use of EPB-TBM, case study: Tabriz Metro, Iran. Bull Eng Geol Environ. https://doi.org/10.1007/ s10064-015-0797-7

34. Motazedian D, Atkinson G (2005) Stochastic finite-fault model based on dynamic corner frequency. Bull Seismol Soc Am 95:995-1010

35. Njock PGA, Shen SL, Zhou A, Lyu HM (2020) Evaluation of soil liquefaction using Al technology incorporating a coupled ENN/tSNE model. Soil Dyn Earthq Eng 130:105988

36. Niknejad SR, Dabiri R (2018) Effects of building construction overburden on liquefaction potential of soils. J Struct Eng Geotech 8(1):19-39

37. Oshnaviey D, Dabiri R (2018) Comparison of standard penetration test (SPT) and shear wave velocity (Vs) method in determining risk of liquefaction potential along Tabriz metro line 2. J Eng Geol 12(2):183-212 (in Persian)

38. Pitilakis K, Gazepis C, Anastasiadis A (2004) Design response spectra and soil classification for seismic code provisions. In: Proceedings of 13th world conference on earthquake engineering. Vancouver, Canada; Paper no. 2904

39. Robertson PK, Wride CE (1998) Evaluation cyclic liquefaction potential using the cone penetration test. Can Geotech J 35:442-459

40. Rodriguez-Marek A, Bray JD, Abrahamson NA (2001) An empirical geotechnical seismic site response procedure. Earthq Spectra 17:65-87

41. Schneider JF, Silva WJ, Stark C (1993) Ground motion model for the 1989 M 6.9 Loma Prieta earthquake including effects of source, path, and site. Earthq Spectra 9:251-287

42. Seed HB, Idriss IM (1971) Simplified procedure for evaluating soil liquefaction potential. J Soil Mech Found Eng Divis ASCE 97(9):1249-1273

43. Seed HB, Idriss IM, Arango I (1983) Evaluation of liquefaction potential using field performance data. J Geotech Eng 109:458-482 
44. Shahri AA, Moud FM (2020) Liquefaction potential analysis using hybrid multi-objective intelligence model. Environ Earth Sci 79(19):1-17

45. Sheikhbaglou T, Hasanpour Sedghi M, Abdi N (2019) Evaluation of liquefaction potential in Barandouz Dam based on cone penetration test (CPT). J New Approaches Civil Eng 2(4):70-82

46. Skempton AK (1986) Standard penetration test procedures and the effects in sands of overburden pressure, relative density, particle size, aging and over consolidation. J Geotech 36:425-447

47. Sonmez H (2003) Modification of the liquefaction potential index and liquefaction susceptibility mapping for a liquefactionprone area (Inegol, Turkey). Environ Geol 44(7):862-871

48. Sonmez H, Gokceoglu C (2005) A liquefaction severity index suggested for engineering practice. Environ Geol 48(1):81-91
49. Xue $X$, Liu E (2017) Seismic liquefaction potential assessed by neural networks. Environ Earth Sci 76(5):2-15

50. Xue X, Yang X, Li P (2017) Application of a probabilistic neural network for liquefaction assessment. Neural Netw World 27(6):557-567

51. Zhang W, Goh AT (2018) Assessment of soil liquefaction based on capacity energy concept and back-propagation neural networks. Integr Disaster Sci Manag 1:41-51

Publisher's Note Springer Nature remains neutral with regard to jurisdictional claims in published maps and institutional affiliations. 